\title{
Clustering of Nicotinic Acetylcholine Receptors: From the Neuromuscular Junction to Interneuronal Synapses
}

\author{
Kyung-Hye Huh and Christian Fuhrer* \\ Department of Neurochemistry, Brain Research Institute, University of Zürich, \\ Winterthurerstrasse 190, CH-8057 Zürich, Switzerland
}

\begin{abstract}
Fast and accurate synaptic transmission requires high-density accumulation of neurotransmitter receptors in the postsynaptic membrane. During development of the neuromuscular junction, clustering of acetylcholine receptors $(\mathrm{AChR})$ is one of the first signs of postsynaptic specialization and is induced by nerve-released agrin. Recent studies have revealed that different mechanisms regulate assembly vs stabilization of AChR clusters and of the postsynaptic apparatus. MuSK, a receptor tyrosine kinase and component of the agrin receptor, and rapsyn, an AChR-associated anchoring protein, play crucial roles in the postsynaptic assembly. Once formed, AChR clusters and the postsynaptic membrane are stabilized by components of the dystrophin/utrophin glycoprotein complex, some of which also direct aspects of synaptic maturation such as formation of postjunctional folds. Nicotinic receptors are also expressed across the peripheral and central nervous system (PNS/CNS). These receptors are localized not only at the pre- but also at the postsynaptic sites where they carry out major synaptic transmission. In neurons, they are found as clusters at synaptic or extrasynaptic sites, suggesting that different mechanisms might underlie this specific localization of nicotinic receptors. This review summarizes the current knowledge about formation and stabilization of the postsynaptic apparatus at the neuromuscular junction and extends this to explore the synaptic structures of interneuronal cholinergic synapses.
\end{abstract}

Index Entries: Clustering; neuromuscular junction; cholinergic; synapse; synaptogenesis; agrin; nicotinic receptors; postsynaptic density.

* Author to whom all correspondence and reprint requests should be addressed. E-mail: chfuhrer@hifo. unizh.ch 


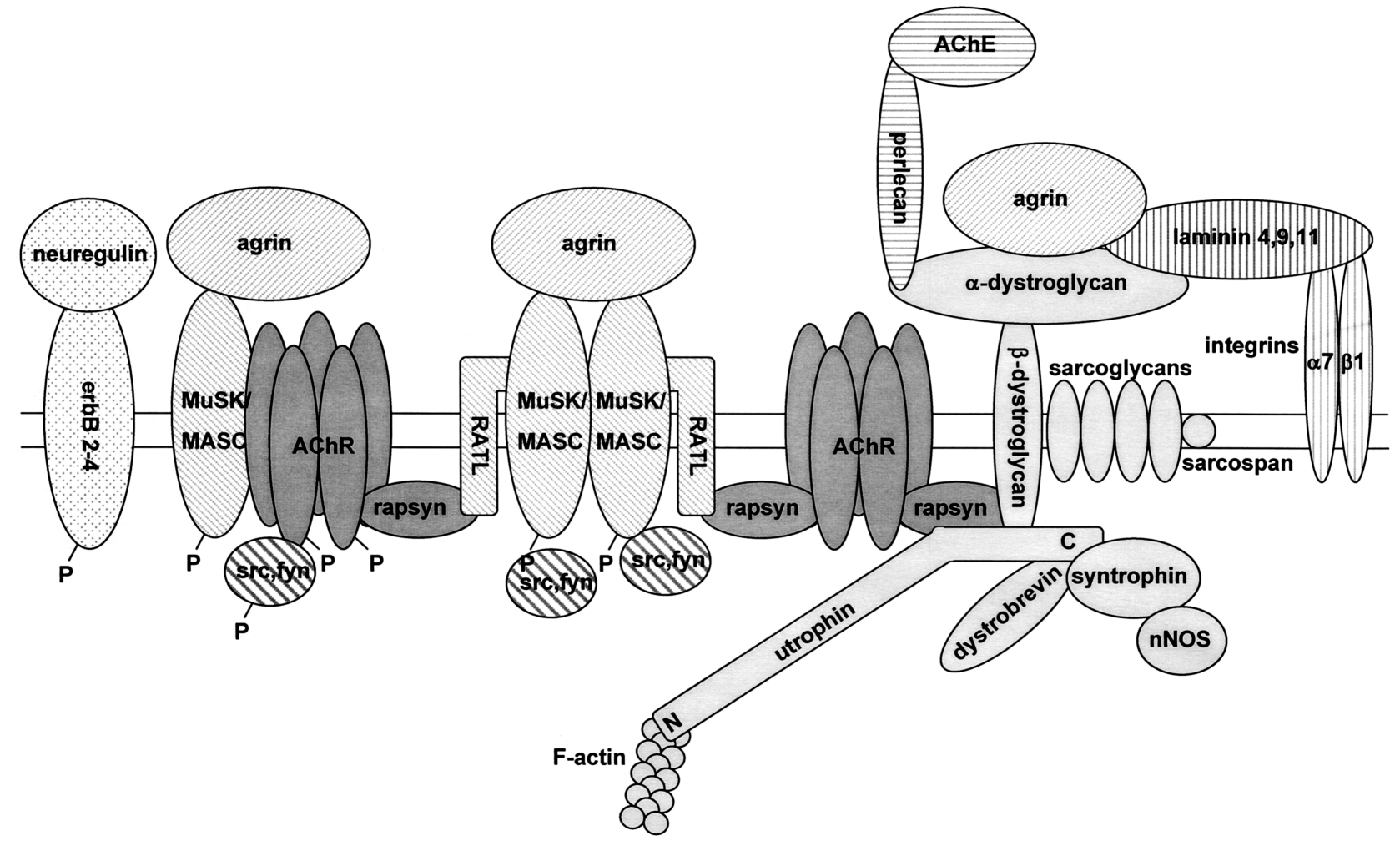

Fig. 1. The postsynaptic apparatus at the neuromuscular junction. Postsynaptic proteins and their interactions are illustrated. For simplicity, not all isoforms of synaptically located proteins are shown. Similarly, segregation of isoforms between the crests and troughs of postjunctional folds is neglected. p, tyrosine phosphorylation.

\section{Introduction}

Synapses are the points of contact between neurons and their target cells, and mediate cellular communication in the nervous system. At chemical synapses, neurotransmitter molecules are released from synaptic vesicles in the presynaptic nerve terminal and activate their receptors in the opposing postsynaptic membrane. To ensure rapid and reliable synaptic transmission, these receptors must be present at a high density in clusters located precisely opposite sites of neurotransmitter release in the nerve ending. Accordingly, clustering of neurotransmitter receptors is a key aspect of synaptogenesis and occurs early during the formation of both central and peripheral synapses (1).
Much of the current knowledge about clustering of neurotransmitter receptors originates from studies on the vertebrate neuromuscular junction (NMJ). At this peripheral cholinergic synapse, many identified proteins interact to form a postsynaptic apparatus in the muscle, whose hallmark is the accumulation of nicotinic acetylcholine receptors (AChRs) in high density, reaching up to 10,000 molecules $/ \mu \mathrm{m}^{2}$ (1; Fig. 1). Neuronal equivalents of this postsynaptic apparatus can be found in synapses in the central nervous system (CNS). One of the best-characterized examples are glutamatergic synapses, where the postsynaptic density contains a plethora of postsynaptic proteins besides glutamate receptors (2).

Several extended reviews about the NMJ have recently appeared (1,3-5), dealing with 
all aspects of NMJ formation, maturation, and elimination. Here, we focus largely on one key aspect of synaptogenesis at the NMJ, the clustering of AChRs, and show possible parallels to localization of neuronal nicotinic receptors at interneuronal cholinergic synapses. Recent studies suggest that different proteins direct formation vs maintenance of $\mathrm{AChR}$ clusters and the postsynaptic apparatus at the NMJ. Therefore, we divide the description of muscle AChR clustering into two main parts, formation vs stabilization.

\section{The Neuromuscular Junction: Formation of AChR Clusters and the Postsynaptic Apparatus}

The high density of postsynaptic AChRs at the adult NMJ is accompanied by a 1000-fold lower level of extrasynaptic AChRs and is the result of three major signaling processes (1). During development, before motorneurons approach muscles, AChRs are diffusely distributed at a density of about 1000 receptors $/ \mu \mathrm{m}^{2}$ throughout muscle fibers. First, upon contact with the nerve ending, these pre-existing AChRs are redistributed to form clusters at sites of nerve-muscle contact. Second, muscle nuclei underneath the nerve terminal start to transcribe genes encoding AChRs at elevated levels. Third, extrasynaptic nuclei cease the transcription of AChR genes. Together, these three processes cause the high density of AChRs in the postsynaptic membrane and the virtual absence of $\mathrm{AChRs}$ throughout the extrasynaptic plasmalemma. In this review, we largely focus on the first of these processes, the clustering of AChRs.

\section{Agrin and Neuregulin Are Two Key Factors for Formation of the NMJ}

During development of the NMJ, AChR clustering is induced by agrin, a key proteoglycan released from the nerve (6). Originally isolated from the electric organ of Torpedo californica based on its ability to cluster AChRs upon addition to cultured myotubes (6), agrin turned out to be the main organizer of the NMJ. Agrin is synthesized by motorneurons, transported along their axons, and released into the extracellular milieu, leading to accumulation in the synaptic basal lamina. In its absence, in agrin-deficient knockout mice, differentiated NMJs fail to form, and nerve-associated clusters of AChRs and other postsynaptic proteins are no longer observed (7). Agrin's crucial role in postsynaptic assembly is further illustrated in microinjected myofibers in vivo, where injection of agrin cDNA causes the local formation of ectopic postsynaptic specializations that contain clustered AChRs in association with many other postsynaptic proteins $(8,9)$. Thus, agrin is both necessary and sufficient to induce AChR clustering and formation of the postsynaptic apparatus. Finally, agrin may also play a role, perhaps indirectly, in presynaptic differentiation, because in agrin-deficient animals, motorneurons grow extensively over muscle fibers of the diaphragm without being restricted to a central endplate zone (7). The signaling pathway of agrin in muscle includes the receptor tyrosine kinase (RTK) MuSK as a key element and will be described below.

AChR transcription by myonuclei underneath the nerve terminal is induced at least in part by neuregulin-1 (NRG-1), a protein expressed by motorneurons and skeletal muscle and concentrated at the NMJ $(3,10)$. NRG-1 is a member of the neuregulin family of differentiation factors and was originally isolated as ARIA (AChR-inducing activity) from chick brain extracts, based on its ability to induce AChR gene expression in cultured myotubes (10). As shown by heterozygous recombinant mice lacking one copy of the NRG-1 gene, NRG-1 is indeed necessary to maintain the high synaptic density of AChRs in vivo (11). NRG-1 acts by activating ErbBs (ErbB2-4), members of the EGF receptor family of RTKs, which are concentrated at the NMJ $(12,13)$. ErbB activation in turn triggers a generic signaling cascade including kinases such as Ras, 
Raf, MAP kinases, and phosphatidylinositol-3kinase, as well as the adapter protein Shc and the tyrosine phosphatase SHP2 (14-17). Together, activation of these signaling intermediates culminates in enhanced transcription of AChR genes in synaptic nuclei. This transcription is thought to be mediated by binding of members of the ets family of transcription factors, such as GABP $\alpha$ and GABP $\beta$, to N-box motifs in the regulatory regions of the $A C h R$ subunit genes $(18,19)$.

Interestingly, recent studies indicate that the agrin and NRG-1 signaling pathways, which both contribute to the high density of AChRs in the postsynaptic membrane, are linked, and that agrin acts upstream of NRG-1 in the formation of the NMJ. Thus, besides clustering of pre-existing AChRs, agrin can induce $\mathrm{AChR}$ gene expression in cultured myotubes (20) and in injected myofibers in vivo $(21,22)$. Furthermore, NRG-1 binds to agrin in vitro, and agrininduced $\mathrm{AChR}$ gene transcription is dependent on signaling through ErbB2 in cultured myotubes (23). As ErbBs are no longer clustered at mutant NMJs of mice lacking agrin (7), these observations suggest that agrin acts upstream of NRG-1 in postsynaptic differentiation, by inducing clustering of NRG-1 receptors, thereby enabling NRG-1 to locally stimulate AChR gene transcription in subsynaptic nuclei.

\section{MuSK, a Component of the Agrin Receptor}

Despite a long-standing interest in the mechanisms of agrin signaling and postsynaptic assembly, many steps in agrin-induced clustering of pre-existing AChRs remain uncertain. It is clear, however, that neurally released agrin activates a receptor in the muscle membrane, which initiates a signaling cascade that ultimately leads to clustering and anchoring of AChRs via intracellular and AChR-associated signaling and anchoring proteins $(1,6)$. A key component of the functional agrin receptor is the RTK, MuSK. The crucial role of this RTK is best illustrated by MuSK-deficient mice, which lack differentiated NMJs, clusters of AChRs and other postsynaptic proteins, and thus display a similar phenotype as agrin $-/-$ mice (24). Moreover, cultured MuSK -/- myotubes fail to respond to agrin, whereas agrin triggers a rapid tyrosine phosphorylation of MuSK when added to wild-type muscle cells, further showing that MuSK is a part of the agrin receptor (25).

In analogy to certain other RTKs that require co-receptors to bind to their extracellular ligands, MuSK itself is unable to directly bind to agrin (25). This observation has led to the proposal that other proteins of myotubes (designated MASC, for myotube-associated specificity component) associate with MuSK to form a fully functional agrin receptor. The nature of MASC, however, has remained largely elusive, although MASC most likely interacts with the first immunoglobulin-like domain in the extracellular part of MuSK (26). Based on its tight binding to agrin, $\alpha$-dystroglycan, which is a component of the dystrophin/utrophin glycoprotein complex (D/UGC), was originally proposed to form part of a functional agrin receptor, thus being a candidate for MASC. Subsequent studies have shown, however, that agrin fragments that do not bind to $\alpha$-dystroglycan still induce AChR clustering and activate MuSK (27-29), and that agrin-induced MuSK activation is normal in antisense-treated myotubes that express low levels of $\alpha$-dystroglycan (30). Thus, $\alpha$-dystroglycan does not seem to be the MASC coreceptor for MuSK.

Another important question is how, following stimulation by agrin, MuSK transmits a signal into myotubes. By analogy with other RTKs, MuSK signaling is expected to involve binding of signal-transducing molecules to phosphorylated tyrosine residues in the cytoplasmic domain of agrin-activated MuSK. Following treatment with agrin, MuSK indeed undergoes autophosphorylation, probably on several cytoplasmic tyrosine residues (31). By mutational analysis, two of these tyrosines were found to be required for agrin-induced $\mathrm{AChR}$ clustering in myotubes. One tyrosine is located in the activation loop of the kinase 
domain, showing that the kinase activity of MUSK is necessary for its responsiveness to agrin $(26,32)$. In addition, a juxtamembrane tyrosine is required as well and can, along with the sequences surrounding it, actually confer agrin responsiveness when expressed in otherwise inactive MuSK-TrkA chimeras (32). As the juxtamembrane tyrosine occurs within an NPXY sequence context, the consensus binding site for Shc and related adapter proteins, one or several Shc-like proteins are likely to be involved as downstream mediators in the agrin signaling pathway.

\section{Rapsyn, an AChR Clustering Protein}

A central player in the agrin signaling pathway downstream of MuSK is rapsyn. This protein was originally identified as a $43 \mathrm{kDa}$ protein in Torpedo synaptic membranes based on its close association with AChRs (33). Rapsyn is necessary for clustering of AChRs and many aspects of postsynaptic differentiation in muscle. Thus, rapsyn-deficient mice lack aggregates of AChRs, dystroglycan, utrophin and ErbB receptors, and cultured rapsyn -/myotubes do not form AChR clusters spontaneously nor even in response to agrin (34). Because MuSK is still localized synaptically at mutant NMJs in these mice and is tyrosinephosphorylated by agrin in rapsyn -/myotubes, rapsyn clearly acts downstream of MuSK (35).

The mechanism of rapsyn-dependent clustering of AChRs has been extensively analyzed by protein expression in heterologous cells. In transfected nonmuscle cells, rapsyn causes clustering of itself, and, upon coexpression, of AChRs and certain other postsynaptic proteins such as MuSK or dystroglycan. This suggests that rapsyn is a general mediator of protein clustering (36-38). Rapsyn has a unique protein structure in which an N-terminal myristoylation site is followed by eight tetratricopeptide repeats (TPR), a coiled-coil motif, a ring zincfinger motif, and a serine phosphorylation site (reviewed in ref. 39). By heterologous expression, some of these domains were found to mediate distinct aspects of rapsyn functioning. First, N-terminal myristoylation mediates targeting of rapsyn to the plasma membrane $(40,41)$. Second, at least two of the eight TPRs are necessary and sufficient for self-association of rapsyn as clusters in transfected cells, whereas, third, the coiled-coil motif is required for co-clustering of AChRs in rapsyn aggregates $(40,42)$. Furthermore, rapsyn clusters each of the $A C h R$ subunits in heterologous cells and requires the intracellular portion of the subunit for this, as shown by the AChR $\alpha$ subunit (43). Together, these recent studies suggest that rapsyn interacts with the cytoplasmic moieties of all subunits of the AChR and that rapsyn self-association and rapsyn-induced $\mathrm{AChR}$ clustering are mediated by different domains in rapsyn.

Rapsyn also causes clustering of MuSK and dystroglycan upon co-expression in QT-6 cells, and biochemical evidence shows that rapsyn directly binds to the cytoplasmic portion of $\beta$-dystroglycan (44). In the case of MuSK, the interaction, unexpectedly, does not depend on the cytoplasmic tail of MuSK, but involves the fourth immunoglobulin-like domain in MuSK's exodomain, leading to the concept that a rapsyn-associated transmembrane linker protein (RATL) links rapsyn to the exodomain of MuSK (Fig. 1; 26,35). This linker, whose identity remains unsolved, may recruit rapsyn and its associated proteins to MuSK and thereby play a crucial role in agrin signaling.

These results are largely based on studies performed using heterologous cell systems and may not be entirely applicable to myotubes, where clustering is regulated in different and/or additional ways: in myotubes, efficient AChR clustering requires agrin and MuSK, and the clusters are much larger. In myotubes, indeed, the expression level of rapsyn is an important parameter that determines its ability to mediate agrin-induced AChR clustering. Endogenous rapsyn normally occurs in about a 1:1 stoichiometry with the AChR in muscle (45). Upon overexpression of rapsyn in wild-type or rapsyn -/- 
myotubes, fewer spontaneous and agrininduced AChR clusters are seen than in cells expressing physiological levels of rapsyn $(46,47)$. This effect appears to originate from intracellular accumulation of AChRs in the case of high rapsyn expression, implying a role of rapsyn in trafficking of AChRs to the plasma membrane (48). Consistent with such a role, rapsyn was recently colocalized with AChRs in post-Golgi transport vesicles of Torpedo electric organ (49). Another example illustrating the differences between heterologous and muscle cells is the zinc ring finger domain of rapsyn, which is dispensable for rapsyn-induced AChR clustering in heterologous cells but not for spontaneous AChR aggregation in myotubes $(42,50)$. These studies suggest that in myotubes, rapsyn functioning depends on interaction with other, as yet unidentified muscle-specific proteins.

\section{Downstream Agrin Signaling: a Role of AChR $\beta$ Phosphorylation and Src-Family Kinases}

Prominent other steps in the agrin signaling pathway downstream of MuSK are tyrosinephosphorylation of the AChR and a link of the AChR to the cytoskeleton. Four recent studies now show that phosphorylation of the AChR $\beta$ subunit and Src-family kinases play a role in these processes and hence for formation and stabilization of AChR clusters (51-54).

In myotubes in culture, agrin induces tyrosine phosphorylation of the AChR $\beta$ and $\delta$ subunits as well as a link of the AChR to the cytoskeleton, as shown by AChR extraction assays $(52,55,56)$. Also, developing NMJs in vivo contain phosphotyrosine-proteins that codistribute with AChRs, and AChRs at these junctions are progressively stabilized, presumably through a link to cytoskeletal elements $(57,58)$. In agrin-treated myotubes, AChR $\beta$ and $\delta$ phosphorylation occur early before clusters are visible (52); $\beta$ phosphorylation is paralleled by decreased extractability of the AChR, which also precedes clustering (55). Several strategies have been applied to determine whether the AChR phosphorylation induced by agrin plays a role in AChR clustering and cytoskeletal linkage. For example, inhibitors of tyrosine kinases, such as herbimycin and staurosporine, block both agrin-induced AChR $\beta$ and $\delta$ phosphorylation and clustering $(52,56$, 59). Conversely, increasing AChR phosphorylation by treatment of myotubes with pervanadate causes an increased cytoskeletal link of AChRs (60). Most importantly, when mutated AChRs, lacking cytoplasmic tyrosine residues in their $\beta$ subunits, are expressed in transfected myotubes, they are still able to form agrininduced clusters (61), but the extent of clustering and their cytoskeletal linkage are clearly reduced when compared to wild-type AChRs (51). Thus, agrin-induced phosphorylation of the AChR $\beta$ subunit regulates the link of the $\mathrm{AChR}$ to the cytoskeleton and contributes to clustering of AChRs.

Another issue is which kinase(s) causes phosphorylation of the AChR subunits in response to agrin and what role such a kinase plays in agrin-induced AChR clustering. MuSK is unlikely to directly phosphorylate the AChR, as illustrated in rapsyn -/myotubes and staurosporine-treated wildtype myotubes, in which agrin activates MuSK, whereas AChR $\beta$ and $\delta$ phosphorylation and clustering are blocked $(35,52,62)$. These studies strongly imply the existence of some other kinase(s) downstream of MuSK. Accumulating evidence suggests that this kinase(s) is a member of the Src-family: first, Src and Fyn are associated with AChRs in myotubes (63), whereas Fyn and Fyk are major kinases in Torpedo electric organ and associate with AChRs in this tissue $(64,65)$. Second, Src can phosphorylate AChR $\beta$ fusion proteins containing the tyrosine residue that is phosphorylated in agrin-treated myotubes $(51,63)$. Third and most importantly, AChRbound Src family members are activated and tyrosine-phosphorylated in agrin-treated myotubes, and this activation is abolished by staurosporine and not observed in rapsyndeficient myotubes, and thus correlates 
highly with AChR clustering (52). Fourth, similarly, each of the Src family kinases Src, Fyn and Fyk can interact with rapsyn in transfected fibroblasts, leading to an activation of these kinases and phosphorylation of cotransfected AChRs (66). Fifth, Src and Fyn form a complex with MuSK in myotubes, are able to phosphorylate MuSK, and their binding to MuSK depends on their SH2 domain and is increased by agrin (53). Sixth, of significance, in myotubes, the agrin-induced linkage of AChRs to the cytoskeleton is blocked by a specific inhibitor of the Src family, PP1, and agrin-induced $\mathrm{AChR}$ clustering is reduced by expression of dominant-negative, kinase-inactive Src, resulting in $\mathrm{AChR}$ aggregates that are very small (53). Finally, by using knockout mice, the role of Src and Fyn in postsynaptic differentiation, AChR clustering and phosphorylation was directly tested (54). In mice lacking Src and Fyn, all aspects of synaptic development examined such as innervation, AChR gene expression, and clustering of postsynaptic proteins are normal until around birth, by which time these animals die (54). In cultured Src-Fyn-deficient myotubes derived from these mice, agrin causes normal AChR clustering and AChR $\beta$ phosphorylation, and the Src-family kinase Yes is upregulated. Interestingly, following withdrawal of agrin, agrin-induced clusters of AChRs are dramatically less stable in myotubes lacking Src and Fyn than in wild-type cells (54).

Together, these recent studies show that kinases of the Src family play a role in agrin signaling: they interact with MuSK in an agrindependent manner and are activated by agrin locally, when bound to the AChR. Further, their functioning is required to link the AChR to the cytoskeleton and for growth of $\mathrm{AChR}$ clusters. Src and Fyn themselves, however, are dispensable for AChR clustering and phosphorylation, although, in their absence, Yes may compensate. Nonetheless, Src and Fyn are clearly required to stabilize agrin-induced AChR aggregates, showing that the mechanisms for formation vs stabilization of these clusters are different.

\section{Protein Interactions and Steps in Formation of the Postsynaptic Apparatus: Evidence for Postsynaptic Pre-Assembly}

Src-family kinases interact both with MuSK and the AChR in myotubes. In both cases, some interaction occurs before addition of agrin, thus revealing the existence of preassembled protein complexes. However, these interactions appear to reflect two distinct pools of Src-family kinases that respond differently to treatment with agrin. Thus, agrin causes Src members to increasingly bind to MuSK (53), but activates AChR-associated Src kinases without affecting their interaction with AChRs (52). Furthermore, agrin induces MuSK phosphorylation independently of rapsyn (35), implying that Src-mediated MuSK phosphorylation (53) does not require rapsyn. In contrast, activation of AChR-bound Src members by agrin critically depends on rapsyn (52). Therefore, there is increasing evidence for the existence of two independent pre-assembled signaling complexes in myotubes, a MuSKbound complex and an AChR-bound complex (Fig. 2).

How do these complexes contribute to postsynaptic assembly? The available evidence suggests that the MuSK-bound complex acts as a primary synaptic scaffold and is clustered first due to agrin; this scaffold then recruits pre-assembled AChR complexes via rapsyn (Fig. 2). These steps of postsynaptic assembly are based, first, on the observation that MuSK is the only identified postsynaptic protein to still be clustered at mutant synapses of rapsyn-deficient mice (35). In addition, when expressed ectopically in injected muscle fibers in vivo, a constitutively active form of MuSK is able to organize postsynaptic specializations containing AChRs in association with most other postsynaptic components (67). Second, rapsyn induces aggregation of AChRs, dystroglycan, MuSK, and of itself when expressed in heterologous cells (36-38), suggesting that rapsyn recruits other postsynaptic components to the MuSK scaffold. Third, in cultured 


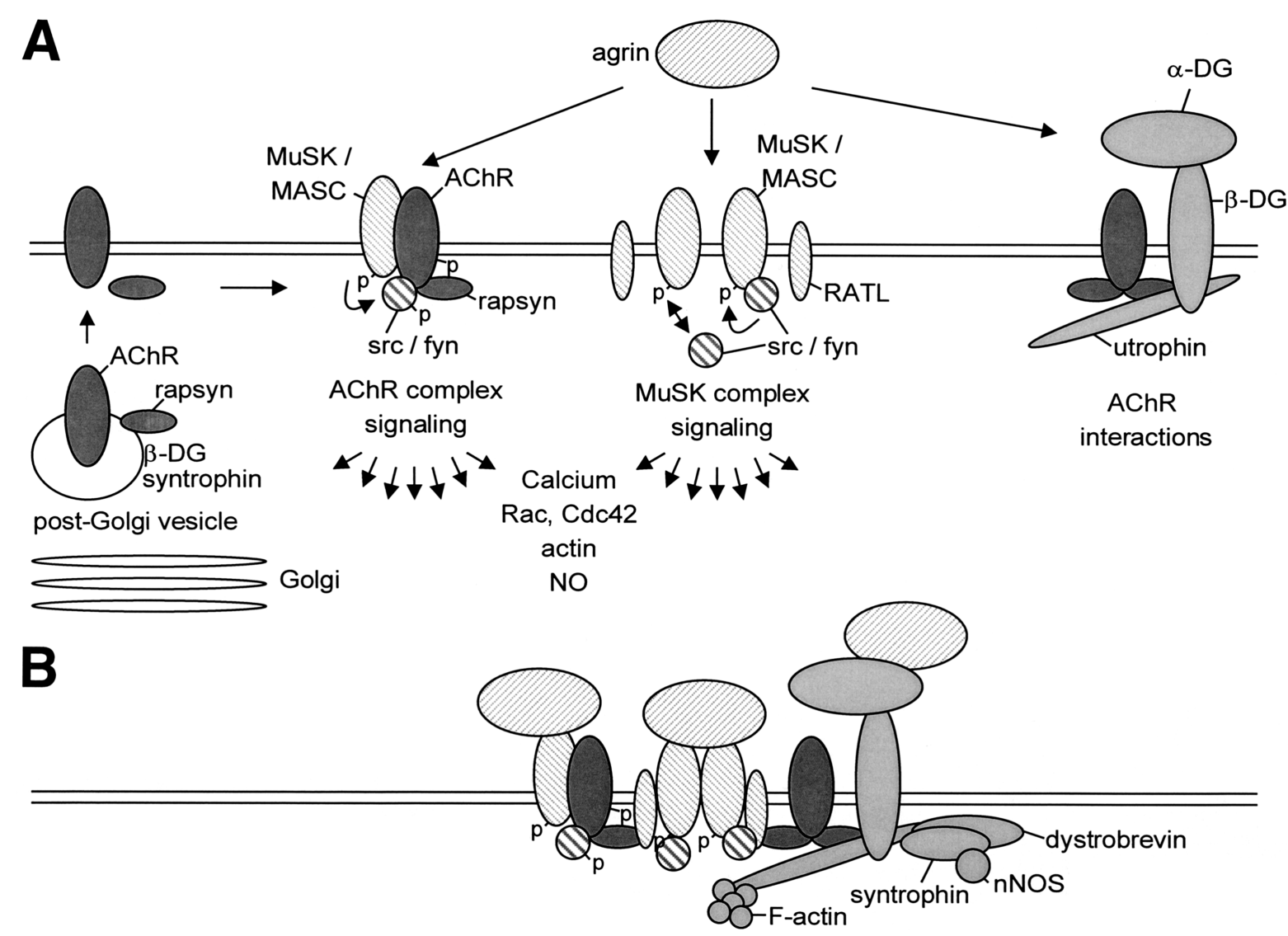

Fig. 2. Steps in the assembly of the postsynaptic membrane at the NMJ. (A) In the absence of nerve-derived agrin, at least two pre-assembled signaling complexes exist in the muscle membrane, an AChR complex and a MuSK complex. Assembly of these complexes may in part occur in the secretory pathway, since some of their components colocalize in post-Golgi vesicles. Two main local signaling events leading to AChR clustering in response to agrin are depicted. In the MuSK complex, which may act as a primary synaptic scaffold, agrin causes rapid activation of MuSK and recruitment of Src and Fyn to MuSK, leading to MuSK phosphorylation. In the AChR complex, agrin activates MuSK rapidly; in a rapsyn-dependent way, AChR-bound Src and Fyn are then autophosphorylated, and AChR $\beta$ and $\delta$ subunits are tyrosine-phosphorylated. Further elements involved are Calcium fluxes, activation of Rac and Cdc42, $\mathrm{NO}$ and actin filaments, which are all required for formation of AChR clusters. (B) After prolonged treatment with agrin, clusters of postsynaptic proteins are formed, at least in part by a rapsyn-dependent linkage of the pre-assembled AChR complexes shown in (A) to the MuSK complex/primary synaptic scaffold. $\alpha$-DG, $\alpha$-dystroglycan; $p$, tyrosine phosphorylation.

myotubes, AChRs interact with rapsyn, MuSK, Src-family kinases, dystroglycan, and utrophin independently of agrin, showing that diffusely distributed AChRs can pre-assemble pools of postsynaptic components including rapsyn (68). Such complexes associate with MuSK-presumably the MuSK primary synaptic scaffold-in response to agrin, leading to a rapsyn-dependent increase in the AChR-MuSK interaction, whereas other AChR-protein interactions are not affected by agrin (Fig. 2; 68). Fourth, intracellular AChRs of Torpedo electric organ are colocalized with rapsyn, dystroglycan, and syntrophin in post- 
Golgi transport vesicles, implying that some formation of pre-assembled AChR complexes may occur intracellularly (69).

Taken together, these studies imply an active functional role of AChRs in synaptic assembly. Consistent with this idea, agrin does not induce clusters of acetylcholinesterase in myotubes where AChRs were downregulated with anti-AChR antibodies (70). Further, agrininduced clustering of a full set of postsynaptic markers requires the presence of AChRs in myotubes, as shown recently in derivatives of C2 myotubes expressing low levels of AChRs, as well as by using C2 myotubes in which surface AChRs were downregulated by antiAChR antibodies (71a). In particular, after downregulating AChRs by treating with antibodies, clusters of rapsyn were not produced in response to agrin (71a). Thus, accumulating evidence suggests that AChRs play an active and early role in postsynaptic assembly, at least in part by forming complexes with other postsynaptic components, which are preassembled prior to the treatment of agrin (Fig. 2).

\section{Other Signaling Intermediates in Agrin- Induced AChR Clustering: Calcium, GTPases, and nNOS}

Agrin-induced postsynaptic assembly (Fig. 2) is likely to be regulated by additional signaling intermediates. Calcium fluxes are required for $\mathrm{AChR}$ clustering, as shown by inhibition of agrin-induced AChR clustering by the fast calcium chelator, BAPTA-AM (72). Furthermore, Rac and Cdc42 are necessary for agrin-induced clustering of AChRs in myotubes, because dominant-negative forms of these small GTPases inhibit aggregation of AChRs in transfected myotubes (73). Rac and Cdc42 are known from other systems to control actin polymerization, for example, causing focal reorganization of the actin cytoskeleton in response to extracellular cues. Indeed, latrunculin A inhibits agrin-induced $\mathrm{AChR}$ clustering in cultured Xenopus muscle cells, confirming the importance of F-actin assembly in AChR aggregation (74). It is unclear, however, how F-actin acts in AChR clustering. A synaptic component of the D/UGC, utrophin, binds to actin but is dispensable for $\mathrm{AChR}$ clustering (75), implying that actin acts through other binding proteins.

Another signaling mediator that was recently recognized to play a role in agrininduced $\mathrm{AChR}$ aggregation is nitric oxide, $\mathrm{NO}$ (76). Neuronal nitric oxide synthetase, nNOS, was known for several years to be concentrated at NMJs, through binding to isoforms of syntrophin, components of the D/UGC (1). Recently, nNOS was found to be co-clustered with AChRs in agrin-treated cultured myotubes (77), and NO was identified as a downstream mediator in agrin-induced AChR clustering and $\mathrm{AChR} \beta$ phosphorylation, as shown by using NOS inhibitors and $\mathrm{NO}$ donors (76). The targets of NO could, in principle, involve Src family kinases, as these are activated by $\mathrm{NO}$ in fibroblasts; this idea is attractive because of the activation of Src-family kinases by agrin in myotubes and their role in stabilization of AChR clusters $(52,54)$.

\section{AChR Clustering by Laminin}

Besides agrin, a number of other factors stimulate AChR clustering when added to cultured muscle cells. These include laminin $(78,79)$ and VVA-B4, a lectin that binds synapse-specific carbohydrates (80). In addition, basic fibroblast growth factor (bFGF) and heparin-binding growth-associated molecule are also active in clustering when bound to polystyrene beads $(81,82)$. The relevance of many of these factors for AChR clustering and NMJ development in vivo is unclear. However, laminin is of particular interest, as it is present synaptically throughout formation of the NMJ and colocalizes with $\mathrm{AChR}$ clusters both in vivo and in vitro (83), suggesting that laminin may provide a supplemental pathway for AChR clustering besides agrin. In the adult, laminin is a major component of the musclefibre basal lamina, with distinct synaptic and extrasynaptic isoforms. Laminin molecules are 
heterotrimers composed of three chains, $\alpha, \beta$, and $\gamma$, which exist in multiple forms encoded by separate genes, giving raise to many laminin isoforms. The basal lamina at mature NMJs contains three major laminin forms, laminin-4 $(\alpha 2 \beta 2 \gamma 1)$, laminin-9 $(\alpha 4 \beta 2 \gamma 1)$, and laminin-11 ( $\alpha 5 \beta 2 \gamma 1)$ (Fig. 1), whereas laminin-2 $(\alpha 2 \beta 1 \gamma 1)$ is the predominant extrasynaptic isoform found in adult muscle and transiently present at developing NMJs (84). Laminin-1 $(\alpha 1 \beta 1 \gamma 1)$, in turn, is expressed early in skeletal muscle development and around the time of initial synapse formation. A crucial role in neuromuscular synaptogenesis has been shown for the $\beta 2$ chain. In $\beta 2$-deficient mice, synaptic organization is aberrant: postsynaptic folds are reduced, the number of active zones in the nerve terminal is decreased, and Schwann cells extend processes into the synaptic cleft (85). Schwann cell intrusion originates from the absence of laminin-11, which normally prevents Schwann cell entry by inhibiting growth of their processes (86).

Binding of agrin to laminin appears to form the basis for the localization and tight association of agrin with the muscle basal lamina. The N-terminal portion of the major isoform of agrin in the PNS, designated as the NtA domain $(87,88)$, binds with high affinity to laminin-1, -2, and particularly well to the synaptic laminin-4 (89). Binding occurs through the coiled coil domain of the $\gamma_{1}$ chain $(90,91)$. This binding may thus contribute to synaptic localization of agrin and suggests that both laminin and agrin act together in synaptic development.

Laminin-1 and merosin (laminin-2/4) cluster AChRs when added to cultured myotubes $(78,79,92)$. The laminin signaling pathway is different from that of agrin and does not involve MuSK or tyrosine phosphorylation of AChRs $(78,79)$. Laminin-induced AChR clustering occurs with a slower time-course and leads to higher densities of AChRs in clusters than in the case of agrin. Moreover, the laminin clustering pathway involves dystroglycan, as shown both in antisense myotube derivatives expressing very low amounts of dystroglycan, and in myotubes differentiated from dystroglycan -/embryonic stem cells, where laminin fails to cause AChR aggregation (78,93). Laminin signaling may also involve integrins, because $\alpha_{7} \beta_{1}$ integrins are coclustered with AChRs in response to laminin, and as anti- $\alpha_{7}$ antibodies modulate the AChR clustering ability of laminin (Fig. 1; 94). This is consistent with the postsynaptic localization of several forms of these receptors at endplates, in particular, $\alpha_{3}, \alpha_{7}, \alpha_{\mathrm{v}}$, and $\beta_{1}$ (5). Interestingly, integrins are also suggested to act as modulators in agrin signaling, in particular, the $\alpha_{v} \beta_{1}$ heterodimer (95), based on antibody inhibition experiments. In addition, cells overexpressing $\alpha_{\mathrm{v}}$ and $\beta_{1}$ integrin adhere to agrin, revealing a possible binding of agrin to this particular integrin.

Thus, integrins, in particular those containing $\beta_{1}$, appear to be involved in laminin as well as agrin signaling. Accordingly, besides their differences, agrin and laminin share some of their signaling mechanisms, explaining the additive effects of agrin and laminin on AChR clustering in myotubes (79). Together, these studies indicate that agrin and laminin can act in concern to lead to maximal AChR clustering, which may be important for postsynaptic differentiation at the NMJ in vivo.

\section{Role of Oligosaccharides in AChR Clustering}

Carbohydrates that terminate in N-acetylgalactosamine ( $\beta$ GalNAc) are selectively enriched at the NMJ and react with specific lectins such as VVA-B4 (80). Recent studies have shown that several factors that bind to and/or modify oligosaccharides, preferentially complex-type N-linked sugars, can induce AChR clustering in cultured myotubes, thus raising the possibility that such oligosaccharides contribute to AChR aggregation during formation of the NMJ in vivo. These factors include VVA-B4, neuraminidase, and $\alpha$-galactosidase $(80,96,97)$. While VVA-B4 acts via a pathway independent of MuSK and AChR phosphorylation, possibly via $\alpha$-dystroglycan (98), neuraminidase increases MuSK 
and AChR phosphorylation, indicating that oligosaccharides may be involved both in agrin-dependent and agrin-independent mechanisms of AChR clustering. Of particular interest are VVA-B4-reactive sugars containing $\beta$ GalNAc. At the NMJ, $\beta$ GalNAc occurs in the context of a defined oligosaccharide structure, the CT carbohydrate antigen, which contains the disaccharides Galp1,3GalNAc and Galß1,4GlcNAc as prominent components (99). Both of these disaccharides induce AChR clustering in myotubes as well as MuSK autophosphorylation in vitro, as shown by in vitro phosphorylation assays (99). Interestingly, agrin contains a mucin-like domain to which lactosamine-like saccharides are attached. Fragments of agrin containing the mucin domain stimulate MuSK autophosphorylation in vitro, which can be inhibited by adding Gal $\beta 1,3 \mathrm{GalNAc}$ or Gal $\beta 1,4 \mathrm{GlcNAc}$. Finally, these disaccharides bind to agrin and MuSK in vitro (99).

The CT antigen thus can serve a similar function to that proposed for the MuSK coreceptor MASC, since it can bind to agrin and MuSK, and stimulate the MuSK kinase activity. Therefore, the CT carbohydrate may act as MASC. It remains to be determined on which protein the active CT carbohydrates are present, and which protein(s) are recognized by VVA-B4 at NMJs in vivo.

\section{Stabilization of AChR Clusters and Maturation of the Postsynaptic Apparatus}

During development of the NMJ, AChR clusters are formed rapidly after contact between motorneuron and muscle. At birth, clustered AChRs are homogenously arranged in a flat postsynaptic membrane underneath the nerve, muscle fibers are multiply innervated, and several nerve terminals are intermingled over the postsynaptic apparatus (1). In the first weeks of postnatal development, competitive mechanisms between these motoneurons lead to synapse elimination. Another aspect of postnatal maturation is the formation of postjunctional folds, leading to segregation of some proteins to become concentrated either at the crests or in the troughs of these folds. AChRs, for example, are localized at the crests, whereas sodium channels are located in the troughs. Using knock-out mice, recent studies indicate that components of the D/UGC, while largely dispensable for initial AChR clustering, are essential both for consolidation and stabilization of AChR clusters as well as for formation of postjunctional folds.

\section{The D/UGC is Required for Stabilization of AChR Clusters and Postnatal Maturation of the Postsynaptic Membrane}

The D/UGC links the cytoskeleton of muscle fibers to their extracellular matrix and thereby stabilizes the muscle sarcolemma (100). Differential localization of members of the complex gives rise to synaptic and extrasynaptic variants of the D/UGC. At NMJs, utrophin, $\beta 2$-syntrophin, and $\alpha$-dystrobrevin- 1 are highly concentrated and virtually absent from extrasynaptic areas, whereas $\alpha$-syntrophin, $\alpha$-dystrobrevin- $2, \alpha$ - and $\beta$-dystroglycan, and dystrophin are found both at NMJs and extrasynaptic areas $(38,101,102)$. Additional components of the complex, the sarcoglycans and sarcospan, are found synaptically and extrasynaptically as well (100). Extracellular binding partners for the synaptic D/UGC are agrin and laminin isoforms (laminin chains $\beta_{2}, \alpha_{5}$, and $\left.\alpha_{4}\right)$, which are all concentrated at NMJs (Fig. 1). The largest components of the D/UGC, utrophin and dystrophin, are necessary for the integrity of muscle fibers but largely dispensable for NMJ formation. Utrophin-deficient mice have a surprisingly mild phenotype in that they appear healthy and viable, and have functional NMJs $(75,103)$. The density of synaptic AChRs is slightly reduced, and formation of postjunctional folds after birth is less pronounced. Likewise, NMJs 
of $m d x$ mice, which lack functional dystrophin, are largely normal, apart from a reduced number of postsynaptic folds. This reduction may result from muscle-fiber necrosis and cycles of regeneration rather than from the absence of dystrophin per se $(104,105)$. These relatively minor effects on morphology of the NMJ in utrophin $-/-$ and $m d x$ mice could, in principle, be due to partial compensation between the two proteins. Accordingly, double-deficient mice lacking both dystrophin and utrophin develop a severe muscular dystrophy closely resembling human Duchenne muscular dystrophy $(106,107)$. However, even in these animals, NMJs are remarkably normal, displaying subtle postsynaptic defects such as reduced AChR density and less postsynaptic folds. This suggests that the D/UGC as such is not essential for formation of the NMJ and AChR clusters, but rather for their maturation, in particular, formation of postsynaptic folds.

A component of the D/UGC involved in consolidation and maintenance of AChR clusters and the NMJ is dystroglycan (Table 1). As dystroglycan-deficient mice die at E6.5, before muscles are formed, chimaeric mice were generated by injecting dystroglycan -/- embryonic stem cells into blastocytes of wild-type; these chimeras lack dystroglycan in many striated muscles (108). Dystroglycan-deficient muscles of these mice develop severe muscular dystrophy and, in adult animals, NMJs are fragmented and lack the typical high density of AChRs and AChEsterase. Instead, AChRs are distributed over an increased area, with a coordinate increase in nerve terminal size at these junctions (93). Agrin-induced AChR clustering was analyzed by using myotubes generated from dystroglycan -/- embryonic stem cells. Agrin still induces substantial AChR clustering in these cells, but utrophin, $\alpha$-dystrobrevin, laminin chains, perlecan, and AChEsterase are not found at these clusters $(93,109)$. As in vivo in chimaeric mice, the area of agrin-induced AChR clusters is increased in dystroglycan -/- myotubes, and the clusters actually consist of many microclusters and disperse rapidly after withdrawal of agrin. Simi- larly, formation of AChR clusters of normal size is severely compromised in antisense derivatives of C2 myotubes expressing low amounts of dystroglycan (30). As phosphorylation of MuSK and AChR $\beta$ subunits is unchanged in these antisense cell lines, dystroglycan and the D/UGC as such are not necessary for $\mathrm{AChR}$ clustering per se, and dystroglycan is not a coreceptor for MuSK. Overexpression of dystroglycan can decrease AChR clustering at developing Xenopus NMJs, however, most likely by adsorbing agrin and preventing it form normal signaling via MuSK (110). Together, these data indicate that dystroglycan is required for integrity of the D/UGC and serves as a membrane anchor to recruit components of the complex to the plasma membrane. Furthermore, dystroglycan is required for consolidation of AChR microclusters into clusters of normal size and for stabilization of AChR aggregates and the NMJ.

Similarly, $\alpha$-dystrobrevin isoforms are necessary to stabilize AChR clusters (Table 1). Mice deficient for $\alpha$-dystrobrevin develop muscular dystrophy due to the absence of D/UGClinked signaling by nNOS, which normally binds to dystrobrevin (111). At the NMJ of these animals, initial synapse formation proceeds relatively normally, but postnatal maturation is affected, because less postsynaptic folds are formed and contain AChRs at crests as well as in troughs, and because AChR-rich areas become fragmented in older animals (109). Synaptic localization of dystrobrevinbinding proteins such as $\alpha$ - and $\beta_{2}$-syntrophin or nNOS, but not other D/UGC components, is reduced in the mutants. Finally, in cultured myotubes, agrin induces normal clustering of AChRs, but these clusters disperse rapidly upon withdrawal of agrin (109). Dystrobrevin is thus necessary for stabilization of AChR clusters in vitro and in vivo and for formation of postsynaptic folds with characteristic segregation of AChRs between crests and troughs. As NMJs in triple knockout mice lacking utrophin, dystrophin, and $\alpha$-dystrobrevin are not dramatically different from single dystrobrevin knockouts (109), essential synaptic 
Table 1

Proteins Necessary for Stabilization of AChR Clusters

\begin{tabular}{|c|c|c|c|}
\hline Protein & $\begin{array}{l}\text { Effect of absence } \\
\text { of active protein }\end{array}$ & Experimental approach & Reference \\
\hline \multirow[t]{2}{*}{ Dystroglycan } & $\begin{array}{l}\text { Fragmentation of postsynap- } \\
\text { tic membrane, muscular } \\
\text { dystrophy }\end{array}$ & $\begin{array}{l}\text { Chimaeric mice lacking } \\
\text { dystroglycan in some } \\
\text { muscle fibers }\end{array}$ & \multirow[t]{2}{*}{$\begin{array}{l}\text { Cote et al., } 1999 \\
\text { (108); Jacobson } \\
\text { et al., } 2001 \text { (93) }\end{array}$} \\
\hline & $\begin{array}{l}\text { Rapid dispersal of frag- } \\
\text { mented AChR clusters }\end{array}$ & $\begin{array}{l}\text { Withdrawal of agrin from } \\
\text { agrin-treated dystroglycan- } \\
\text { deficient myotubes }\end{array}$ & \\
\hline \multirow[t]{2}{*}{ Dystrobrevin } & $\begin{array}{l}\text { Fragmentation of postsynap- } \\
\text { tic membrane, less } \\
\text { postjunctional folds, mus- } \\
\text { cular dystrophy }\end{array}$ & $\alpha$-dystrobrevin $-/-$ mice & \multirow[t]{2}{*}{$\begin{array}{l}\text { Grady et al., 1999, } \\
2000(111,109)\end{array}$} \\
\hline & $\begin{array}{l}\text { Rapid dispersal of AChR } \\
\text { clusters }\end{array}$ & $\begin{array}{l}\text { Withdrawal of agrin from } \\
\text { agrin-treated } \alpha \text {-dystro- } \\
\text { brevin }-/- \text { myotubes }\end{array}$ & \\
\hline \multirow[t]{2}{*}{ Src and Fyn } & Normal NMJ around birth & Src-Fyn-deficient mice & \multirow[t]{2}{*}{ Smith et al., 2001} \\
\hline & $\begin{array}{l}\text { Rapid dispersal of } \mathrm{AChR} \\
\text { clusters }\end{array}$ & $\begin{array}{l}\text { Withdrawal of agrin from } \\
\text { agrin-treated src -/-; fyn } \\
\text {-/- myotubes }\end{array}$ & \\
\hline \multirow[t]{2}{*}{ TrkB } & $\begin{array}{l}\text { Disruption of AChR clusters } \\
\text { at the NMJ }\end{array}$ & $\begin{array}{l}\text { Adenovirus-mediated expres- } \\
\text { sion of dominant-negative } \\
\text { TrkB in muscle in mice }\end{array}$ & \multirow[t]{2}{*}{$\begin{array}{l}\text { Gonzalez et al., } \\
1999 \text { (118) }\end{array}$} \\
\hline & Disruption of AChR clusters & $\begin{array}{l}\text { Adenoviral expression of } \\
\text { dominant-negative TrkB in } \\
\text { agrin-treated myotubes }\end{array}$ & \\
\hline
\end{tabular}

functions of the D/UGC seem to be mediated by dystrobrevin, probably by localizing its associated signaling molecules to the NMJ.

Finally, absence of $\alpha$-syntrophin leads to structurally aberrant synapses (112). The isoforms of syntrophin show differential localization at the adult NMJ. Whereas $\alpha$-syntrophin is found at the crests and in the troughs of postsynaptic folds, $\beta_{2}$-syntrophin occurs mainly in the troughs; the $\beta_{1}$ isoform is not concentrated at the NMJ (102). In the absence of $\alpha$-syntrophin, muscle fibers appear healthy histologically and the mice are mobile and fertile (113). NMJs of these animals lack utrophin and
nNOS, have reduced levels of AChRs and AChEsterase and show abnormal postsynaptic folds with fewer openings to the synaptic cleft (112). $\alpha$-syntrophin thus mediates localization of utrophin and nNOS to the NMJ, and the similarities in NMJs between $\alpha$-syntrophinand utrophin-deficient mice suggest that $\alpha$ syntrophin functions to localize utrophin at the synapse, which organizes postsynaptic fold formation.

Together, studies on knockouts of components of the D/UGC show that this complex is largely dispensable for initial formation of AChR clusters and the NMJ. Instead, the com- 
plex is mainly required for postnatal maturation of the postsynaptic membrane as well as for stabilization of AChR clusters.

\section{Tyrosine Kinases Are Required for Stabilization of Agrin-Induced AChR Clusters}

Three lines of evidence have recently indicated that, in addition to the D/UGC, tyrosine kinases are important for the stability of agrininduced AChR clusters. First, upon removal of agrin, the kinase inhibitors herbimycin and staurosporine disperse pre-formed AChR clusters in myotubes (56), showing that tyrosine kinase activity is necessary to maintain AChR clusters. This activity most likely originates from another kinase than MuSK, because staurosporine does not affect the autophosphorylation of MuSK (62).

Second, Src and Fyn mediate stabilization of AChR clusters, because in myotubes cultured from Src-Fyn-doubly deficient mice, agrin induces normal phosphorylation and aggregation of AChRs, but these clusters disperse rapidly after withdrawal of agrin (54). Src and Fyn are thus dispensable for AChR clustering, but essential for cluster stabilization. PP1 and PP2, inhibitors of Src-family kinases, do not decrease the stability of AChR aggregates, suggesting that cluster stabilization does not primarily require the kinase activities of Src and Fyn, but rather their presence as adapters, by mediating protein interactions (54; Table 1). These findings reveal interesting parallels to focal adhesion sites, where Src, independent of its kinase activity, can recruit and activate other proteins such as focal adhesion kinase (FAK) $(114,115)$. Furthermore, multiple tyrosine kinases, including Src, FAK, and Pyk2, can complement each other to achieve optimal adhesion on fibronectin (116), raising the possibility that interaction of multiple kinases may regulate interactions between the postsynaptic membrane and cytoskeleton elements at the NMJ, thereby stabilizing AChR clusters. In support of this, several cytoskeletal proteins such as talin, paxillin, and $\alpha$-fodrin can be tyrosinephosphorylated and are concentrated at the mammalian NMJ or in Torpedo synaptic membranes (117).

Third, TrkB is also involved in cluster stabilization. Disruption of TrkB-mediated signaling, by overexpression of a dominant-negative form of TrkB, decreases the stability of AChR clusters in vivo and in agrin-treated cultured myotubes (Table $1 ;$ 118). TrkB is localized to the postsynaptic membrane in muscle and can associate with Fyn in cortical neurons $(118,119)$, raising the possibility that TrkB signaling mediated by Src-family kinases stabilizes AChR clusters in muscle. The ligand for TrkB mediating this effect is not known. BDNF, a prominent ligand of TrkB, and NT-4 inhibit agrin-induced AChR clustering in cultured myotubes (120). TrkB may thus exert two different effects at the NMJ, depending on the stage of NMJ differentiation. Early in postsynaptic assembly, it may-stimulated by $\mathrm{BDNF}$ - negatively regulate $\mathrm{AChR}$ clustering, while later it stabilizes the postsynaptic membrane.

Together, these studies show that several tyrosine kinases, at least Src, Fyn, and TrkB, are involved in stabilization of AChR clusters. The mechanisms for formation vs stabilization of AChR clusters are thus different, both in terms of structural proteins, as reflected by the D/UGC, as well as in their requirement for signaling proteins, as shown in the case of Src, Fyn, and TrkB. It remains to be determined whether and how tyrosine kinases and the D/UGC collaborate to achieve optimal stabilization. One possible link is dystrobrevin, which is a substrate for tyrosine kinases and strongly tyrosine-phosphorylated in Torpedo electric organ (121). Although $\alpha$ dystrobrevin is neither required for early steps in agrininduced AChR clustering nor tyrosine-phosphorylated by agrin stimulation (101), its phosphorylation may play a role in stabilization of AChR clusters at the developing NMJ. This would be consistent with the striking similarity in dispersal of AChR clusters in dystrobrevin -/- and Src-Fyn-deficient myotubes, as 
well as in muscle cells overexpressing dominant-negative TrkB (Table 1).

\section{A Role of AChRs in Postsynaptic Stabilization}

During postnatal NMJ development, the composition of AChRs changes, as the embryonic $\gamma$ subunit is replaced by the adult $\varepsilon$ chain. By deleting the $\varepsilon$ gene in mouse, the role of AChRs in this phase of NMJ development was analyzed. In $\varepsilon-/-$ mice, the high postsynaptic density of AChRs is gradually reduced in the first weeks after birth, as these animals fail to synthesize adult-type AChRs $(122,123)$. Consequently, the mice develop gradual muscle weakness and atrophy, and die prematurely. Along with the reduced AChR density, postjunctional folds disappear, in such a way that the postsynaptic membrane, although rich in folds at $20 \mathrm{~d}$, is flattened out by $60 \mathrm{~d}$ of age (124). Further, postsynaptic components such as rapsyn, utrophin, MuSK, erbB4, phosphotyrosine, and dystrobrevin are reduced as the AChR density decreases $(122,124)$. Interestingly, rapsyn disappears strictly in parallel with AChRs, while utrophin and dystrobrevin lag behind (124). Thus, $\varepsilon$-containing AChRs are required for synaptic localization of rapsyn and maintenance of the postsynaptic apparatus at the postnatal NMJ, including postjunctional folds.

In addition, activity through the AChR is necessary to maintain its high synaptic density (125). In adult mice, AChRs are highly metabolically stabilized, displaying a half-life of about $14 \mathrm{~d}$. Immediately after blocking AChRs by $\alpha$-bungarotoxin (BTX), the half-life is reduced to less than a day, resulting in rapid turnover of postsynaptic AChRs and a decrease in the density of postsynaptic AChRs. This decrease in half-life can be stopped by direct stimulation of muscle or restoration of synaptic transmission (125). These data indicate that AChR activation is required for its synaptic stability and that AChRs serve structural roles in maintaining the postsynaptic apparatus. AChRs thus appear to be necessary for both formation and maintenance of the postsynaptic apparatus at the NMJ.

\section{Nicotinic Receptors in the Nervous System}

Multiple classes of neurotransmitter receptors localized at the synapse of a neuron and different setup of synaptic excitability of target cells suggest that synaptic features, which have been characterized in the muscle, might not simply be translated into the nervous system. Differently from the muscle type, nicotinic receptors in the nervous system are characterized by high $\mathrm{Ca}^{2+}$ permeability and considerable diversity of their subunits. So far, nine different $\alpha\left(\alpha_{2,3,4,5,6,7,8,9,10)}\right)$ and three different $\beta$ subunits $\left(\beta_{2,3,4}\right)$ have been identified in vertebrates, which are encoded by distinct genes (126-128). Differential splicing of some of the genes further extends this already existing list of clones (129).

Functional subtypes of receptors that can be generated from different arrays of subunits are equally diverse although they all appear to form a pentameric structure $(127,130) . \alpha_{7}, \alpha_{8}$, and $\alpha_{9}$ subunits form a homo-oligomeric complex when expressed as a single subunit and comprise the $\alpha$-bungarotoxin (BTX)-binding class of AChRs. The $\alpha_{7}$ subunit is one of the most abundant subunits that are expressed in the vertebrate nervous system and $\alpha_{7}$ receptors are characterized by high $\mathrm{Ca}^{2+}$ permeability that is comparable to NMDA receptor channels $(131,132)$. Other subunits require $\alpha$ or $\beta$ to be functional as a hetero-oligomer. Prominent examples are $\alpha_{4} \beta_{2}$, which is the most abundant subtype in the brain and forms high-affinity nicotine binding sites, and ganglionic subtypes of receptors containing $\alpha_{3}, \alpha_{5}, \beta_{2}$, and $\beta_{4}$. Expression of multiple subunit genes in the same neuronal population suggests that, in reality, the profile of subtypes of neuronal receptors is much more complex $(126,133,134)$.

Mechanisms of cholinergic synaptogenesis in the nervous system are largely elusive com- 
pared to the NMJ and have been mainly investigated in the PNS. Studies about the CNS synapses have been limited, mainly due to the relatively low expression level of nicotinic receptors in limited areas of the CNS. Thus, compared to other receptor systems, very little information is available about how interneuronal cholinergic synapses in the CNS are built up and maintained. In the following parts, studies that have been made so far for characterizing nicotinic synapses in the PNS and CNS are summarized, and we attempt to postulate postsynaptic components of these synapses, mainly based on the information about the molecules identified at the NMJ.

\section{Cholinergic Synapses in the Peripheral Nervous System}

Functional cholinergic synapses have been identified in a number of peripheral neurons from various species, e.g., superior cervical, ciliary, and sympathetic ganglia (135-137). In the PNS, nicotinic receptors mediate excitatory synaptic transmission as major neurotransmitter receptors, although a presynaptic function, regulating the release of neurotransmitters, has also been demonstrated $(134,138)$.

Postsynaptic structures and functional aspects of interneuronal cholinergic synapses are best-characterized in chick ciliary ganglia where developmental and innervation profiles have been well-investigated. Chick ciliary ganglion neurons express $\alpha_{3}, \alpha_{5}, \beta_{2}, \beta_{4}$, and $\alpha_{7}$ subunits and, thus far, two major subtypes of receptors differing in their subunit-compositions and also functional properties have been identified, that is, the $\alpha$-BTX sensitive component comprised of $\alpha_{7}$ subunits and MAb35immunoreactive receptors of which at least two classes exist depending on the presence of $\beta_{2}$ subunits, e.g., $\alpha_{3} \alpha_{5} \beta_{2} \beta_{4}$ and $\alpha_{3} \alpha_{5} \beta_{4}$ (139-141). In the chick ciliary ganglion, $\alpha_{7}$ and mAb35AChRs show interesting differences in their localizations with respect to synaptic sites. Whereas clusters of $\alpha_{3} / \alpha_{5}$ subunit-containing ganglionic receptors are found at extrasynaptic sites in addition to postsynaptic densities, those of $\alpha_{7}$-containing receptors that represent the most abundant population of ganglionic receptors, are exclusively localized on perisynaptic somatic spines $(135,142)$. By ultrastructural analysis, synaptic MAb35-AChRs were localized to the postsynaptic density (PSD) opposing presynaptic vesicle release sites. Perisynaptic $\alpha_{7}$ receptors on spines, interestingly, are present in close proximity to the potential release sites overlaid with vesicles $(142,143)$. Although $\alpha_{7}$ subunits are excluded from the synapse, they carry majority of the synaptic current and it appears that they are important for rapid and reliable synaptic firing $(144,145)$.

What mechanisms could be involved in anchoring/targeting of these receptors at their respective sites? Recent studies show that in chick ciliary ganglia actin filaments are colocalized with $\alpha_{7}$ receptors and are active components for maintaining $\alpha_{7}$ receptor-clusters in the postsynaptic membrane, since depolymerization of actin filaments disperses these clusters and also accelerates agonist-challenged rundown of the $\alpha_{7}$ channel function $(142,146)$. In addition to association, either directly or indirectly, with f-actin, anchoring perisynaptic $\alpha_{7}$ receptors on somatic spines appears to involve other mechanisms, since these receptors are resistant to extraction by nonionic detergents even after treatment with actindepolymerizing agents (142). A recent study has demonstrated that $\alpha_{7}$ receptor clusters are tightly linked to membrane lipid rafts. As shown by treatments that disperse rafts, the integrity of these rafts is required to maintain $\alpha_{7}$ clusters, independently of $\mathrm{f}$-actin, thus offering an explanation for an additional anchoring mechanism (147). Lipid rafts are rich in Srcfamily kinases and other signaling molecules (148). This suggests that Src and Fyn might play a role in maintaining $\alpha_{7}$ clusters and this could be an interesting parallel to the NMJ where these kinases are necessary to maintain AChR clusters (54). In contrast, ganglionic MAb35-reactive receptors, although partly found on somatic spines along with $\alpha_{7}$, appear 
to require different mechanisms for localization in the plasma membrane since their functional integrity is not affected by repeated applications of nicotine and they are also readily solubilized by nonionic detergents $(142,146)$. These receptors are targeted to the postsynaptic density by a signal in the cytoplasmic portion of the $\alpha_{3}$ subunit: studies using chimeric receptor constructs showed that the cytoplasmic loop of the $\alpha_{3}$ subunit mediates postsynaptic localization, whereas the corresponding region of $\alpha_{5}$ lacks such targeting information (149). Another candidate for localization of neuronal AChRs is rapsyn, based on its importance at the NMJ. Although rapsyn causes clustering and detergent-insolubility of various nicotinic receptors upon expression in heterologous fibroblasts, it is not required for clustering of ganglionic $\mathrm{AChRs}$ in the superior cervical ganglion neurons, as shown in rapsyn -/- mice (see below;137). Further, although mRNA is present, postsynaptic rapsyn immunoreactivity was not detected in this ganglion nor in chick ciliary ganglia, indicating that rapsyn might play a different role, if any at all, in the nervous system.

Another complexity of interneuronal cholinergic synapses originates from the presence of glycine receptor-microdomains that are associated with the postsynaptic densities of chick ciliary neurons (143). Chick gephyrin specifically colocalizes with these glycine receptors, but not with MAb35-reactive AChRs. Segregation of different neurotransmitter receptors and different subtypes of receptors into mosaics of domains, using cognate clustering/anchoring molecules, thus, may be another mechanism for the neuron to fine-tune synaptic transmission.

Finally, extrasynaptic clusters of nicotinic receptors, in addition to clustering at the postsynaptic sites, have also been observed in the mouse superior cervical ganglion and the frog cardiac ganglion $(137,150)$, which raises the possibility that nonsynaptic localization of nicotinic receptors, yet taking part in a significant portion of synaptic transmission, might be a general feature of peripheral nicotinic synapses. Although NMDA receptors in cultured hippocampal cells were found clustered extrasynaptically in early neuronal development, molecular explanations have not been provided. Further, clustering of ligand-gated ion channel receptors outside of postsynaptic sites in mature neurons has not been ubiquitously found and investigated (151).

\section{Cholinergic Synapses in the Central Nervous System: An Overview}

Autoradiographic and subunit mapping studies using various ligands, antibodies, and cRNA probes have generated useful information about the distribution of nicotinic receptors and cholinergic synapses in the CNS (130). Although these studies implicated cholinergic functions in the brain, unequivocal identification of cholinergic synapses carrying nicotinic receptors as the mediator of major synaptic transmission turned out to be difficult and has been limited to few examples (152). This has been attributed to the presynaptic role of nicotinic receptors as a primary function and examples are well-documented by numerous studies where presynaptic functions are shared by a variety of neurotransmitters, e.g., glutamate, dopamine, GABA, noradrenaline, and ACh itself (134). However, a collection of recently made studies, mostly using immunocytochemical and refined-electrophysiological analysis, begun to generate accumulating evidence for the postsynaptic cholinergic function, indicating that nicotinic receptors can act as the major carrier of synaptic current. In the following section, studies that provided direct or indirect evidence for the role of nicotinic receptors in mediating rapid synaptic transmission are summarized and discussed.

\section{Immunocytochemical Characterization of Cholinergic Synapses}

$\alpha_{7}, \alpha_{4}$, and $\beta_{2}$ subunits are widely expressed species of subunits in the brain, while expression profiles of other subunits are more limited 
(153-155). Some of the areas where these subunits are abundantly expressed served as good model system for investigating postsynaptic aspects of cholinergic synapses. However, a number of neurons express multiple subunits simultaneously and the question of how these are organized as synaptic responsive elements at the synapse is elusive and remains to be investigated.

Strong $\alpha_{4}$ immunoreactivity has been mapped to tyrosine hydroxylase (TH)-positive dopaminergic neurons in substantia nigra pars compacta (SNpc) and ventral tegmental area, of which cell bodies and dendrites are innervated by neurons from pedunculopontine tegmental nuclei (PPN) and the laterodorsal tegmental nucleus (156-158). Postsynaptic nicotinic responses that can be evoked by stimulating inputs from PPN and also excitability of dopaminergic neurons in SNpc by application of nicotine indicate that nicotinic receptors directly mediate synaptic transmission in these neurons $(159,160)$. Dopaminergic neurons express multiple nicotinic subunits and studies from different lines suggest that the $\alpha_{4} \beta_{2}$ combination of receptors among others are likely candidates for functional nicotinic receptors mediating fast synaptic transmission (161-164). Light microscopic and ultrastructural analysis revealed some features of subcellular distribution of $\alpha_{4}$ subunits. $\alpha_{4}$-immunoreactivity was associated with cell perikarya and dendritic shafts, but not with spines $(158,160)$. Labeling of some postsynaptic structures was evident as assessed by electron microscopic analysis, but some nonsynaptic labeling was also identified. Further, a detailed study using postembedding immunogold procedures demonstrated clear labeling of $\alpha_{4}$ at the PSD, although the frequency of the labeling was low (158).

So far, studies that demonstrated association of nicotinic receptor subunits with the PSD in the CNS have been limited to $\alpha_{4}$ subunits. Although $\alpha_{4}$ subunits decorate the PSD at very low frequency in dopaminergic neurons of the substantia nigra, PSD association has been demonstrated more convincingly in other brain areas such as the paraventricular nucleus of the hypothalamus and pyramidal cells in layer 5 of the rat cortex $(165,166)$. The common theme arising from these studies is the distribution of $\alpha_{4}$ subunits in the cell body and proximal rather than distal parts of dendrites. It is notable that $\beta_{2}$ subunits, which preferentially assemble with $\alpha_{4}$ subunits and form highaffinity nicotine binding sites, also exclusively label perikarya with rare synaptic labeling in the brain as judged by electron microscopic analysis (154).

Another example for fast synaptic nicotinic responses is found in the chick lateral spiriform nucleus (SpL) that receives cholinergic projections from the nucleus semilunaris. Nicotinic synapses have been identified by the double-label immunofluorescence technique using antibodies to choline acetyltransferase (ChAT) and MAb35 (167). ChAT-positive immunoreactivity was associated with that of MAb35 more preferentially in the fibers lateral to SpL than in neurons in the nucleus, and colocalization was pronounced in dendrites but not on the neuronal soma of these neurons. The clusters of MAb35immunoreactive nicotinic receptors were not frequently colocalized with presynaptic vesicle markers, suggesting that most of clusters are of nonsynaptic origins (168). However, stimulation of cholinergic afferents to SpL neurons generated nicotinic excitatory postsynaptic potentials (EPSPs) that can evoke action potentials (167). These responses were not sensitive to antagonists for $\alpha_{7}$ receptors and might be mediated by $\alpha_{5}, \beta_{2}$ subunit-containing receptors since they are expressed by more than $90 \%$ of the neurons in the SpL (168). Thus, nicotinic receptors in SpL neurons are primarily concentrated at extrasynaptic sites, and yet they participate in eliciting the postsynaptic response.

$\alpha_{7}$ subunits that constitute $\alpha$-BTX binding sites are enriched in the hippocampus and some nuclei of the brain stem $(155,161)$. Morphological analysis suggests postsynaptic roles of these receptors since there was no significant axon terminal staining. The subcellular staining pattern of $\alpha_{7}$ varied across different neuronal groups in terms of the extent of dendritic label- 
ing, since all dendritic trees were labeled in some cases and, in others, only very proximal portion of dendrites were labeled. Even with frequent labeling across the brain, functional $\alpha_{7}$ receptors mediating fast synaptic transmission have been conclusively identified only in interneurons of the hippocampus (see below). In contrast with the PNS, clustered postsynaptic patch type of immunostaining was not observed at least in tissue sections. However, in a separate in vitro study using cultured neurons from the hippocampus, clusters of $\alpha_{7}$ subunits were observed along the soma and dendrites and they were colocalized with presynaptic markers $(169,170)$. Since most of these cultured neurons are pyramidal cells, this has been interpreted as segregation of $\alpha_{7}$ subunits into presynaptic terminals of these neurons, regulating the release of glutamate. A physiological parallel is provided by the study where $\alpha_{7}$ receptors enchanced the release of glutamate at the mossy fiber-CA3 pyramidal cell synapses (171). In comparison to $\alpha_{7}, \beta_{2}$ subunits were localized in the cell body in a diffuse way in cultured hippocampal cells, suggesting specific segregation of different subtypes of receptors into different subcellular compartments. The discrepancy between studies using cultured cells and tissue sections for aggregation of $\alpha_{7}$ immunoreactivity could be due to the system used, that is, in vivo vs in vitro, and awaits further detailed characterization.

\section{Functional Evidence for Cholinergic Transmission}

Direct isolation of postsynaptic responses mediated by nicotinic receptors was made possible by recent studies that employed detailed electrophysiological analysis. Thereby, functional cholinergic synapses were demonstrated in various principal cells and interneurons of different brain regions. Spontaneous or nicotinic agonist-mediated postsynaptic responses were observed in a number of brain areas, e.g., neurons in the interpeduncular nucleus and medial habenula $(172,173)$, nucleus ambiguus of the brain stem (174), medial vestibular nucleus (175), and low-threshold spike cells in layer 5 of the rat visual cortex (176).

Fast cholinergic synaptic transmission with interesting physiological implications was found in the developing ferret visual cortex (177), apart from peripheral synapses of retinal ganglion cells (178). Some principal cells and interneurons in the developing ferret visual cortex displayed spontaneous EPSCs and also stimulation of thalamic afferents elicited cholinergic postsynaptic responses. Synaptic currents were insensitive to $\alpha$-BTX, excluding the $\alpha_{7}$ class of receptors. Interestingly, an increase in this widespread nicotinic synaptic transmission coincided with the period of eyeopening, suggesting a role of nicotinic receptors in synaptogenic events or circuit remodeling in this period.

In addition to these studies, with the importance of the hippocampus as a structure mediating learning and memory and with the aid of its relatively well-defined circuitry, much attention has been drawn to the synaptic functions of nicotinic receptors in the hippocampus, revealing detailed aspects of cholinergic functions and also receptor subtypes mediating those. Pyramidal cells and interneurons of the hippocampus receive cholinergic innervation from the medial septum-diagonal band complex of the basal forebrain (179-181). Although $\alpha_{7}$ subtype-mediated synaptic currents have been reported in pyramidal neurons of the CA1 area in some cases, generally they appear not to carry functional nicotinic synapses (182-184). Interneurons in the CAl field, however, express multiple components of nicotinic responses that differ in kinetic properties and pharmacological profiles. Further, different populations of interneurons express different functional subtypes and some express multiple classes of receptors, revealing complexity of the cholinergic synapses. The main, rapidly depolarizing synaptic response in CAl interneurons is mediated by $\alpha_{7}$ receptors, whereas the rest of the slowly depolarizing components are mediated by other classes comprising $\alpha_{2}-\alpha_{5}$ and $\beta_{2}-\beta_{4}$, which overall can be grouped into four pharmacologically differ- 
ent subtypes $(169,184-187)$. In support of electrophysiological observations, $\alpha$-BTX binding sites were found at the underlying synapses on interneuronal somata where cholinergic boutons appear to synapse $(179,188)$. Excitation of these interneurons will influence the activity of a large number of principal cells, thereby coordinating overall hippocampal output (138).

Another intriguing physiological significance of cholinergic synapses in the hippocampus is provided by the study where activation of $\alpha_{7}$ receptors enhances the LTP induction process in the CAl shaffer collateral/commissural pathway (189).

Further approaches, combining electrophysiology with immunocytochemistry using highaffinity antibodies specific for nicotinic subunits, will help to understand better the location and postsynaptic architecture of cholinergic synapses in the CNS.

\section{Postsynaptic Assembly: From the NMJ to the Nervous System}

Anchoring and clustering of neurotransmitter receptors at functional sites are a critical task for neurons to perform efficient synaptic transmission. A number of synaptic components including clustering molecules have been identified for other neurotransmitter receptors $(190,191)$. Especially, existence of multiple isoforms for some synaptic molecules such as the PSD95 family of proteins further impose complicated features of the CNS synapses. However, to date, very little information is available for the question of how cholinergic synapses in the nervous system are constructed and maintained, especially in the CNS. One plausible hypothesis would be that structural and signaling components, which have been characterized at the NMJ, are also involved in the assembly of the postsynaptic scaffold in the nervous system. Indeed, many molecules of the NMJ are also expressed in the PNS and CNS, and some, such as the D/UGC, appear to assemble into functional complexes in a similar way as in the muscle $(192,193)$. However, except rapsyn, the relationship between these proteins and nicotinic synapses has not been systematically investigated so far. Another possibility is that interneuronal cholinergic synapses are associated with as yet unidentified postsynaptic scaffolding proteins. For example, gephyrin, which is involved in clustering of glycine and $\mathrm{GABA}_{\mathrm{A}}$ receptors, does not appear to be a synaptic component of cholinergic synapses (143).

\section{Agrin May Play a Role in Postsynaptic Assembly at CNS Synapses}

Several studies have addressed the question of whether agrin, in analogy to its crucial role at the NMJ, plays a similar role in the formation of CNS synapses, however, the outcome is unclear at present. Agrin is widely expressed in the CNS, with prominent levels in the hippocampus and olfactory bulb (194). In agrin-deficient mice, synaptic localization and clustering of glutamate and $\mathrm{GABA}_{\mathrm{A}}$ receptors were not affected in the hippocampus, neither in tissue sections nor in cultured neurons (195). Similarly, glutamatergic and GABAergic synapses are formed normally in cultured cortical neurons derived from agrin -/- mice, as was tested using immunocytochemical and functional analysis (196). In contrast, in in vitro studies using hippocampal cultured neurons, suppressing the expression of agrin by treatment with antisense oligonucleotides or agrin-antibodies resulted in the formation of fewer synapses that were functionally inefficient $(197,198)$. The discrepancy among these studies might be due to compensatory synaptogenic mechanisms in vivo operating in the agrin-deficient mice. Some indirect lines of evidence also suggest that agrin might be involved in the formation of the interneuronal synapses, including postsynaptic assembly. Agrin expression in the developing cortex coincide with the formation of thalamocortical and intracortical synapses (199). Also, during development of the retina, agrin is redistributed from an initial diffused state to a punctate pattern in the inner and outer plexiform 
layers, where it is concentrated within the synaptic clefts $(200,201)$. Moreover, in cultured retinal neurons, clusters of agrin colocalize at synaptic sites with gephyrin, one of the markers of inhibitory synapses, and purified retinal agrin induces $\mathrm{AChR}$ clustering in cultured myotubes (202). These results suggest a role of agrin in postsynaptic assembly, including receptor clustering, at synapses in the retina. However, in the CNS, studies about localization and expression of agrin have so far not investigated the presence of agrin at synapses in detail. Recently, a new form of agrin in which the NtA domain of the $\mathrm{N}$-terminus is replaced by a cell surface-associating transmembrane domain was isolated from murine species and was found to be expressed mainly in the brain $(88,203)$. This isoform was also able to cluster AChRs in myotube cultures, suggesting that it might play a role in clustering of nicotinic or other receptors at the CNS interneuronal synapses.

With respect to cholinergic synapses, agrin is expressed in neurons of the chick ciliary ganglion (204). Agrin is also expressed by the innervating cholinergic neurons of the Edinger-Westphal nucleus: this expression, along with agrin expression in ganglionic neurons, coincides with the periods of synapse formation and clustering of AChRs (205). In tissue culture, agrin from agrinexpressing Chinese Hamster Ovary (CHO) cells arrests the neurite outgrowth of ciliary neurons and induces aggregation of the synaptic vesicle protein, synaptotagmin, suggesting an effect on presynaptic differentation (206). Therefore, agrin may play roles both in pre- and postsynaptic differentation at cholinergic synapses in the ciliary ganglion, reminiscent of its roles at the vertebrate NMJ.

\section{Rapsyn Is Not Required for Clustering of Ganglionic AChRs}

Rapsyn, which is essential for the formation of AChR clusters at the NMJ, can cluster neuronal nicotinic receptors of $\alpha_{7}, \alpha_{3} / \beta_{2}, \alpha_{3} / \beta_{4}$, or $\alpha_{4} / \beta_{2}$ combinations and the $\alpha_{1}, \beta_{1}, \gamma_{2}-\mathrm{GABA}_{\mathrm{A}}$ receptor complex in heterologous cells $(137,207,208)$. However, evidence supporting rapsyn as a clustering molecule in neurons is lacking. Rapsyn mRNAs, including several shorter splice variants that are not active in clustering of neuronal AChRs (differently from the full-length form), are readily detected in chick ciliary and mouse superior cervical ganglia, while the expression level in the brain is very low $(137,208,209)$. In these studies, however, rapsyn immunoreactivity was not detected in ganglionic neurons $(137,208)$. Most importantly, clusters of ganglionic AChRs containing $\alpha_{5}$ and $\beta_{2}$ subunits are present in normal number, size and densities in superior cervical ganglia of mice lacking rapsyn, showing that rapsyn is not required for clustering of ganglionic AChRs (137). The reason for the expression of rapsyn transcripts without proteins in neurons is not clear, but could imply that, in the nervous system, rapsyn might play a different role than clustering.

\section{Components of the D/UGC Are Associated with Interneuronal Synapses in the PNS and CNS}

Dystrophin, the major component of the $\mathrm{D} / \mathrm{UGC}$ in muscle, is expressed in neurons of the PNS and CNS. Immunohistochemical and biochemical analysis demonstrated that dystrophin is associated with the PSDs in mouse superior cervical ganglia, some neurons of the cortex and cerebellar Purkinje cells, and is found along the soma and dendrites as clusters in the CNS neurons (210-213). In addition to the muscle type, a number of short forms of dystrophin-related gene products that still carry critical interaction domains with other D/UGC proteins have been identified in the nervous system, although functional roles of those are not clear $(192,212,214,215)$. There exists some evidence that these different gene products are localized at different synaptic sites (212). Synaptic functions of dystrophin have been implicated in some studies. Clusters of $\alpha_{1}$ and $\beta_{2}$ subunits of $\mathrm{GABA}_{A}$ receptors were colocalized with dystrophin immunoreactivity in 
the hippocampus and cerebellum and they were markedly reduced in dystrophin-deficient $m d x$ mice, while there was no change in the number of gephyrin clusters (213). This suggests that dystrophin is involved in the synaptic localization of at least some subpopulations of $\mathrm{GABA}_{\mathrm{A}}$ receptors. A possible link between synaptic AChRs and the D/UGC is found in the following studies. Ganglionic axotomy generated a coinciding reversible decrease of immunoreactivity of $\beta$-dystroglycan, dystrophin, and $\alpha_{3}$ AChR subunits in the mouse superior cervical ganglion, which preceded the decrease in the number of intraganglionic synapses (216). In addition, synaptic localization of $\alpha_{3}$ AChR subunits, $\alpha$ - and $\beta$-dystroglycan was reduced in the superior cervical ganglion of $m d x$ mice (which lack full-length dystrophin but still express short dystrophin isoforms). These findings suggests that fulllength dystrophin is involved in the synaptic localization of $\alpha_{3}$, by associating with these receptors in the same synaptic complex (217). Therefore, dystrophin appears to be associated with synaptic $\mathrm{GABA}_{\mathrm{A}}$ and nicotinic receptors eventhough the role as a synaptic component is not entirely clear.

$\beta$-dystrobrevin and $\alpha$-dystrobrevin- 1 , members of the dystrobrevin gene family, are mainly expressed in neurons and glia, respectively (215). $\beta$-dystrobrevin is enriched at postsynaptic densities of major neurons in the brain and its expression pattern resembles that of dystrophin. $\beta$-dystrobrevin can be isolated together with syntrophin and dystrophins from the brain, indicating the presence of a complex similar to the muscle D/UGC $(215,218)$. However, the molecular architecture of these protein complexes appears to be different between the muscle and the brain since, in dystrophin-deficient $m d x$ mice, dystrobrevin-syntrophin complexes are still formed in the brain, whereas their assembly is disrupted in the muscle (215). The presence of $\beta$-dystrobrevin in the brain, but not in the muscle, further illustrates the structural difference of the muscle and brain forms of the D/UGC (214).
Syntrophin, another D/UGC component, also exists as multiple forms encoded by distinct genes. Two novel variants of human origin, $\gamma_{1}$ and $\gamma_{2}$ isoforms, have been cloned recently and are expressed in neurons of the brain, mainly the cortex and hippocampus, decorating the soma and proximal dendrites (219). Other syntrophins $\left(\alpha_{1}\right.$ and $\left.\beta_{2}\right)$ are also expressed in the hippocampus and their mRNAs colocalize with those of dystrophins (192). All of these syntrophin isoforms can bind to dystrophin as shown by in vitro assays $(219,220)$

Dystroglycans and utrophin also are expressed in neurons in an analogous manner to the aforementioned D/UGC proteins, but they appear to also decorate some microvasculature structures and glia $(221,222)$. Utrophin tends to lable neurons differently from dystrophin in a nonoverlapping manner, not only on the cellular but also subcellular levels, suggesting possibly different functional roles between them (223).

Although these studies indicate that components of the muscle D/UGC are widely expressed in the brain, some at synaptic sites, and can form similar complexes, functional roles of these proteins with respect to CNS synapse formation have not been unequivocally established. So far, sodium channels have been isolated as a binding partner for syntrophin, therefore, indicating that components of the D/UGC can be directly associated with neuronal ion channels (224). It remains to be determined whether direct association with neurotransmitter receptors also underlies the suggested role of dystrophin at central GABAergic and peripheral cholinergic synapses (see above).

\section{Possible Roles of Presynaptic Input and the Cytoskeleton in Maintaining Synaptic AChRs}

Maintenance of the high synaptic density of AChRs at the NMJ requires activation of these receptors (125). Some studies suggest that this 
might also be the case for cholinergic synapses in the PNS. In frog cardiac ganglion neurons, large/dense clusters of AChRs at synaptic sites were dispersed into small clusters over the cell surface by denervation (135). However, synaptic activity-dependent activation of receptors does not appear to be necessary for the development of some classes of receptor clusters, as has been mainly investigated by in vitro assays using cultured neurons. Although glutamatergic and glycinergic inputs are necessary for clustering of AMPA and glycine receptors, respectively, clustering of NMDA and GABAA receptors does not require cognate presynaptic input (225-228). Therefore it appears that organization of different classes of synapses requires not only different synaptic modules, but also different modes of activity-based regulation. A close correlate to the NMJ is found in another aspect of the PNS, that is, in chick ciliary ganglion neurons, presynaptic input induces the expression of AChR mRNAs during synaptogenesis and also maintains their expression $(229,230)$.

The cytoskeleton is an important component for anchoring neuronal receptors at synaptic sites, and the regulation of cytoskeletal assembly serves as a mechanism for stabilizing or destabilizing synaptic receptor-complexes for a number of neuronal receptors. So far, tubulin and actin have been identified as cytoskeletal elements that regulate clustering events of GABAA $_{A}$ and glutamate receptors $(191,231,232)$. Interaction of receptors with the cytoskeleton occurs mostly through clustering molecules such as gephyrin, GABARAP, and PSD95, although direct interactions also occur (191,233-235). Evidence for interaction of neuronal nicotinic receptors with the cytoskeleton is limited to ganglionic $\alpha_{7}$ receptors (see above). Although anchoring phenomena at postsynaptic densities found for ganglionic AChR subunits as well as for CNS subunits such as $\alpha_{4}$, suggest involvement of the cytoskeleton for synaptic localization of these receptors, there has been no study supporting this hypothesis.

\section{Conclusions}

Mechanisms of postsynaptic assembly that were established at the NMJ potentially serve as good models for understanding synaptic development of interneuronal synapses. Whether development of the neuronal cholinergic synapses requires some of the molecules that have been identified at the NMJ, or whether it depends on unique build-up machinery, is an intriguing open question. For example, rapsyn, an essential component for clustering of AChRs at the NMJ, is dispensable for clustering of neuronal nicotinic receptors. However, actin filaments are required for maintaining clusters of both muscle and neuronal AChRs and some D/UGC proteins are associated with peripheral cholinergic synapses. Considering different classes of neuronal receptors that are segregated in a given synapse, as demonstrated in peripheral ganglia, it is also tempting to question how these unique synaptic structures and functions are formed and maintained.

\section{Acknowledgments}

We thank Dr. R.A. McKinney for her comments on this review. Work in our lab was supported by the Kanton Zürich, the Dr. Eric Slack-Gyr Foundation, the NCCR on Neural Plasticity and Repair, and by grants from the Swiss National Science Foundation and the Swiss Foundation for Research on Muscle Diseases (to C.F.).

\section{References}

1. Sanes J. R. and Lichtman J. W. (1999) Development of the vertebrate neuromuscular junction. Annu. Rev. Neurosci. 22, 389-442.

2. Husi H., Ward M. A., Choudhary J. S., Blackstock W. P., and Grant S. G. (2000) Proteomic analysis of NMDA receptor-adhesion protein signaling complexes. Nat. Neurosci. 3, 661-669.

3. Burden S. J. (1998) The formation of neuromuscular synapses. Genes Dev. 12, 133-148. 
4. Hoch W. (1999) Formation of the neuromuscular junction. Agrin and its unusual receptors. Eur. J. Biochem. 265, 1-10.

5. Meier T. and Wallace B. G. (1998) Formation of the neuromuscular junction: molecules and mechanisms. Bioessays 20, 819-829.

6. McMahan U. J. (1990) The agrin hypothesis. Cold Spring Harb. Symp. Quant. Biol. 55, 407-418.

7. Gautam M., Noakes P. G., Moscoso L., Rupp F., Scheller R. H., Merlie J. P., and Sanes J. R. (1996) Defective neuromuscular synaptogenesis in agrin-deficient mutant mice. Cell 85, 525-535.

8. Cohen I., Rimer M., Lomo T., and McMahan U. J. (1997) Agrin-induced postsynaptic-like apparatus in skeletal muscle fibers in vivo. Mol. Cell. Neurosci. 9, 237-253.

9. Meier T., Hauser D. M., Chiquet M., Landmann L., Ruegg M. A., and Brenner H. R. (1997) Neural agrin induces ectopic postsynaptic specializations in innervated muscle fibres. J. Neurosci. 17, 6534-6544.

10. Fischbach G. D. and Rosen K. M. (1997) ARIA : a neuromuscular junction neuregulin. Annu. Rev. Neurosci. 20, 429-458.

11. Sandrock A. W., Jr., Dryer S. E., Rosen K. M., Gozani S. N., Kramer R., Theill L. E., and Fischbach G. D. (1997) Maintenance of acetylcholine receptor number by neuregulins at the neuromuscular junction in vivo. Science 276, 599-603.

12. Moscoso L. M., Chu G. C., Gautam M., Noakes P. G., Merlie J. P., and Sanes J. R. (1995) Synapseassociated expression of an acetylcholine receptor-inducing protein, ARIA/heregulin, and its putative receptors, ErbB2 and ErbB3, in developing mammalian muscle. Dev. Biol. 172, 158-169.

13. Zhu X., Lai C., Thomas S., and Burden S. J. (1995) Neuregulin receptors, erbB3 and erbB4, are localized at neuromuscular synapses. EMBO J. 14, 5842-5848.

14. Si J., Luo Z., and Mei L. (1996) Induction of acetylcholine receptor gene expression by ARIA requires activation of mitogen-activated protein kinase. J. Biol. Chem. 271, $19,752-19,759$.

15. Altiok N., Altiok S., and Changeux J. P. (1997) Heregulin-stimulated acetylcholine receptor gene expression in muscle: requirement for MAP kinase and evidence for a parallel inhibitory pathway independent of electrical activity. EMBO J. 16, 717-725.
16. Tanowitz M., Si J., Yu D. H., Feng G. S., and Mei L. (1999) Regulation of neuregulin-mediated acetylcholine receptor synthesis by protein tyrosine phosphatase SHP2. J. Neurosci. 19, 9426-9435.

17. Won S., Si J., Colledge M., Ravichandran K. S., Froehner S. C., and Mei L. (1999) Neuregulinincreased expression of acetylcholine receptor epsilon- subunit gene requires ErbB interaction with Shc. J. Neurochem. 73, 2358-2368.

18. Briguet A. and Ruegg M. A. (2000) The Ets transcription factor GABP is required for postsynaptic differentiation in vivo. J. Neurosci. 20, 5989-5996.

19. Fromm L. and Burden S. J. (1998) Synapsespecific and neuregulin-induced transcription require an ets site that binds GABPalpha/GABPbeta. Genes Dev. 12, 3074-3083.

20. Jones G., Herczeg A., Ruegg M. A., Lichtsteiner M., Kroger S., and Brenner H. R. (1996) Substrate-bound agrin induces expression of acetylcholine receptor epsilon-subunit gene in cultured mammalian muscle cells. Proc. Natl. Acad. Sci. USA 93, 5985-5990.

21. Jones G., Meier T., Lichtsteiner M., Witzemann V., Sakmann B., and Brenner H. R. (1997) Induction by agrin of ectopic and functional postsynaptic-like membrane in innervated muscle. Proc. Natl. Acad. Sci. USA 94, 2654-2659.

22. Rimer M., Mathiesen I., Lomo T., and McMahan U. J. (1997) gamma-AChR/epsilon-AChR switch at agrin-induced postsynaptic-like apparatus in skeletal muscle. Mol. Cell. Neurosci. 9, 254-263.

23. Meier T., Masciulli F., Moore C., Schoumacher F., Eppenberger U., Denzer A. J., et al. (1998) Agrin can mediate acetylcholine receptor gene expression in muscle by aggregation of muscle-derived neuregulins. J. Cell. Biol. 141, 715-726.

24. DeChiara T. M., Bowen D. C., Valenzuela D. M., Simmons M. V., Poueymirou W. T., Thomas S., et al. (1996) The receptor tyrosine kinase MuSK is required for neuromuscular junction formation in vivo. Cell 85, 501-512.

25. Glass D. J., Bowen D. C., Stitt T. N., Radziejewski C., Bruno J., Ryan T. E., et al. (1996) Agrin acts via a MuSK receptor complex. Cell 85, 513-523.

26. Zhou H., Glass D. J., Yancopoulos G. D., and Sanes J. R. (1999) Distinct domains of MuSK 
mediate its abilities to induce and to associate with postsynaptic specializations. J. Cell Biol. 146, 1133-1146.

27. Hopf C. and Hoch W. (1996) Agrin binding to alpha-dystroglycan. Domains of agrin necessary to induce acetylcholine receptor clustering are overlapping but not identical to the alpha-dystroglycan-binding region. J. Biol. Chem. 271, 5231-5236.

28. Gesemann M., Cavalli V., Denzer A. J., Brancaccio A., Schumacher B., and Ruegg M. A. (1996) Alternative splicing of agrin alters its binding to heparin, dystroglycan, and the putative agrin receptor. Neuron 16, 755-767.

29. Hopf C. and Hoch W. (1998) Tyrosine phosphorylation of the muscle-specific kinase is exclusively induced by acetylcholine receptoraggregating agrin fragments. Eur. J. Biochem. 253, 382-389.

30. Jacobson C., Montanaro F., Lindenbaum M., Carbonetto S., and Ferns M. (19980 alpha-Dystroglycan functions in acetylcholine receptor aggregation but is not a coreceptor for agrinMuSK signaling. J. Neurosci. 18, 6340-6348.

31. Watty A., Neubauer G., Dreger M., Zimmer M., Wilm M., and Burden S. J. (2000) The in vitro and in vivo phosphotyrosine map of activated MuSK. Proc. Natl. Acad. Sci. USA 97, 4585-4590.

32. Herbst R. and Burden S. J. (2000) The juxtamembrane region of MuSK has a critical role in agrin-mediated signaling. EMBO J. 19, 67-77.

33. Burden S. J., DePalma R. L., and Gottesman G. S. (1983) Crosslinking of proteins in acetylcholine receptor-rich membranes: association between the beta-subunit and the $43 \mathrm{kd}$ subsynaptic protein. Cell 35, 687-692.

34. Gautam M., Noakes P. G., Mudd J., Nichol M., Chu G. C., Sanes J. R., and Merlie J. P. (1995) Failure of postsynaptic specialization to develop at neuromuscular junctions of rapsyndeficient mice. Nature 377, 232-236.

35. Apel E. D., Glass D. J., Moscoso L. M., Yancopoulos G. D., and Sanes J. R. (1997) Rapsyn is required for MuSK signaling and recruits synaptic components to a MuSK-containing scaffold. Neuron 18, 623-635.

36. Phillips W. D., Kopta C., Blount P., Gardner P. D., Steinbach J. H., and Merlie J. P. (1991) ACh receptor-rich membrane domains organized in fibroblasts by recombinant 43-kildalton protein. Science 251, 568-570.
37. Gillespie S. K., Balasubramanian S., Fung E. T., and Huganir R. L. (1996) Rapsyn clusters and activates the synapse-specific receptor tyrosine kinase MuSK. Neuron 16, 953-962.

38. Apel E. D., Roberds S. L., Campbell K. P., and Merlie J. P. (1995) Rapsyn may function as a link between the acetylcholine receptor and the agrin-binding dystrophin-associated glycoprotein complex. Neuron 15, 115-126.

39. Colledge M. and Froehner S. C. (1998) To muster a cluster: anchoring neurotransmitter receptors at synapses. Proc. Natl. Acad. Sci. USA 95, 3341-3343.

40. Ramarao M. K. and Cohen J. B. (1998) Mechanism of nicotinic acetylcholine receptor cluster formation by rapsyn. Proc. Natl. Acad. Sci. USA 95, 4007-4012.

41. Phillips W. D., Maimone M. M., and Merlie J. P. (1991) Mutagenesis of the 43-kD postsynaptic protein defines domains involved in plasma membrane targeting and AChR clustering. J. Cell Biol. 115, 1713-1723.

42. Ramarao M. K., Bianchetta M. J., Lanken J., and Cohen J. B. (2001) Role of rapsyn tetratricopeptide repeat and coiled-coil domains in self-association and nicotinic acetylcholine receptor clustering. J. Biol. Chem. 276, 7475-7483.

43. Maimone M. M. and Enigk R. E. (1999) The intracellular domain of the nicotinic acetylcholine receptor alpha subunit mediates its coclustering with rapsyn. Mol. Cell. Neurosci. 14, 340-354.

44. Cartaud A., Coutant S., Petrucci T. C., and Cartaud J. (1998) Evidence for in situ and in vitro association between beta-dystroglycan and the subsynaptic $43 \mathrm{~K}$ rapsyn protein. Consequence for acetylcholine receptor clustering at the synapse. J. Biol. Chem. 273, 11,321-11,326.

45. LaRochelle W. J. and Froehner S. C. (1987) Comparison of the postsynaptic 43-kDa protein from muscle cells that differ in acetylcholine receptor clustering activity. J. Biol. Chem. 262, 8190-8195.

46. Yoshihara C. M. and Hall Z. W. (1993) Increased expression of the $43-\mathrm{kD}$ protein disrupts acetylcholine receptor clustering in myotubes. J. Cell Biol. 122, 169-179.

47. Han H., Noakes P. G., and Phillips W. D. (1999) Overexpression of rapsyn inhibits agrininduced acetylcholine receptor clustering in muscle cells. J. Neurocytol. 28, 763-775.

48. Han H., Yang S. H., and Phillips W. D. (2000) Overexpression of rapsyn modifies the intra- 
cellular trafficking of acetylcholine receptors. J. Neurosci. Res. 60, 155-163.

49. Marchand S., Bignami F., Stetzkowski-Marden F., and Cartaud J. (2000) The myristoylated protein rapsyn is cotargeted with the nicotinic acetylcholine receptor to the postsynaptic membrane via the exocytic pathway. J. Neurosci. 20, 521-528.

50. Bezakova G. and Bloch R. J. (1998) The zinc finger domain of the 43-kDa receptor-associated protein, rapsyn: role in acetylcholine receptor clustering. Mol. Cell. Neurosci. 11, 274-288.

51. Borges L. S. and Ferns M. (2001) Agrininduced phosphorylation of the acetylcholine receptor regulates cytoskeletal anchoring and clustering. J. Cell Biol. 153, 1-12.

52. Mittaud P., Marangi P. A., Erb-Vögtli S. E., and Fuhrer C. (2001) Agrin-induced activation of AChR-bound Src family kinases requires rapsyn and correlates with $\mathrm{AChR}$ clustering. J. Biol. Chem. 276, 14505-14513.

53. Mohamed A. S., Rivas-Plata K. A., Kraas J. R., Saleh S. M., and Swope S. L. (2001) Src-class kinases act within the agrin/MuSK pathway to regulate acetylcholine receptor phosphorylation, cytoskeletal anchoring, and clustering. J. Neurosci. 21, 3806-3818.

54. Smith C. L., Mittaud P., Prescott E. D., Fuhrer C., and Burden S. J. (2001) Src, Fyn and Yes are not required for neuromuscular synapse formation but are necessary for stabilization of agrin-induced clusters of acetylcholine receptors. J. Neurosci. 21, 3151-3160.

55. Wallace B. G. (1992) Mechanism of agrininduced acetylcholine receptor aggregation. $J$. Neurobiol. 23, 592-604.

56. Ferns M., Deiner M., and Hall Z. (1996) Agrininduced acetylcholine receptor clustering in mammalian muscle requires tyrosine phosphorylation. J. Cell Biol. 132, 937-944.

57. Froehner S. C. (1991) The submembrane machinery for nicotinic acetylcholine receptor clustering. J. Cell Biol. 114, 1-7.

58. Meier T., Perez G. M., and Wallace B. G. (1995) Immobilization of nicotinic acetylcholine receptors in mouse C2 myotubes by agrininduced protein tyrosine phosphorylation. J. Cell Biol. 131, 441-451.

59. Wallace B. G. (1994) Staurosporine inhibits agrin-induced acetylcholine receptor phosphorylation and aggregation. J. Cell Biol. 125, 661-668.
60. Wallace B. G. (1995) Regulation of the interaction of nicotinic acetylcholine receptors with the cytoskeleton by agrin-activated protein tyrosine kinase. J. Cell Biol. 128, 1121-1129.

61. Meyer G. and Wallace B. G. (1998) Recruitment of a nicotinic acetylcholine receptor mutant lacking cytoplasmic tyrosine residues in its beta subunit into agrin-induced aggregates. Mol. Cell. Neurosci. 11, 324-333.

62. Fuhrer C., Sugiyama J. E., Taylor R. G., and Hall Z. W. (1997) Association of muscle-specific kinase MuSK with the acetylcholine receptor in mammalian muscle. EMBO J. 16, 4951-4960.

63. Fuhrer C. and Hall Z. W. (1996) Functional interaction of Src family kinases with the acetylcholine receptor in C2 myotubes. J. Biol. Chem. 271, 32,474-32,481.

64. Swope S. L. and Huganir R. L. (1993) Molecular cloning of two abundant protein tyrosine kinases in Torpedo electric organ that associate with the acetylcholine receptor. J. Biol. Chem. 268, 25,152-25,161.

65. Swope S. L. and Huganir R. L. (1994) Binding of the nicotinic acetylcholine receptor to SH2 domains of Fyn and Fyk protein tyrosine kinases. J. Biol. Chem. 269, 29,817-29,824.

66. Mohamed A. S. and Swope S. L. (1999) Phosphorylation and cytoskeletal anchoring of the acetylcholine receptor by Src class proteintyrosine kinases. Activation by rapsyn. J. Biol. Chem. 274, 20,529-20,539.

67. Jones G., Moore C., Hashemolhosseini S., and Brenner H. R. (1999) Constitutively active MuSK is clustered in the absence of agrin and induces ectopic postsynaptic-like membranes in skeletal muscle fibers. J. Neurosci. 19, 3376-3383.

68. Fuhrer C., Gautam M., Sugiyama J. E., and Hall Z. W. (1999) Roles of rapsyn and agrin in interaction of postsynaptic proteins with acetylcholine receptors. J. Neurosci. 19, 6405-6416.

69. Marchand S., Stetzkowski-Marden F., and Cartaud J. (2001) Differential targeting of components of the dystrophin complex to the postsynaptic membrane. Eur. J. Neurosci. 13, 221-229.

70. De La Porte S., Chaubourt E., Fabre F., Poulas K., Chapron J., Eymard B., et al. (1998) Accumulation of acetylcholine receptors is a necessary condition for normal accumulation of acetylcholinesterase during in vitro neuro- 
muscular synaptogenesis. Eur. J. Neurosci. 10, 1631-1643.

71. Grow W. A. and Gordon H. (2000) Sialic acid inhibits agrin signaling in C2 myotubes. Cell Tissue Res. 299, 273-279.

71a. Marangi P.A., forsayeth J. r., Mittaud P., ErbVögtli S., Blake D. J., Moransard, M., Sander A., and Fuhrer, C. (2001) Acetylcholine receptors are required for agrin-induced clustering of postsynaptic proteins. EMBO J. 20, 7060-7073.

72. Megeath L. J. and Fallon J. R. (1998) Intracellular calcium regulates agrin-induced acetylcholine receptor clustering. J. Neurosci. 18, 672-678.

73. Weston C., Yee B., Hod E., and Prives J. (2000) Agrin-induced acetylcholine receptor clustering is mediated by the small guanosine triphosphatases Rac and Cdc42. J. Cell Biol. 150, 205-212.

74. Dai Z., Luo X., Xie H., and Peng H. B. (2000) The actin-driven movement and formation of acetylcholine receptor clusters. J. Cell Biol. 150, 1321-1334.

75. Grady R. M., Merlie J. P., and Sanes J. R. (1997) Subtle neuromuscular defects in utrophindeficient mice. J. Cell Biol. 136, 871-882.

76. Jones M. A. and Werle M. J. (2000) Nitric oxide is a downstream mediator of agrin-induced acetylcholine receptor aggregation. Mol. Cell. Neurosci. 16, 649-660.

77. Luck G., Hoch W., Hopf C., and Blottner D. (2000) Nitric oxide synthase (NOS-1) coclustered with agrin-induced AChR-specializations on cultured skeletal myotubes. Mol. Cell. Neurosci. 16, 269-281.

78. Montanaro F., Gee S. H., Jacobson C., Lindenbaum M. H., Froehner S. C., and Carbonetto S. (1998) Laminin and alpha-dystroglycan mediate acetylcholine receptor aggregation via a MuSK-independent pathway. J. Neurosci. 18, 1250-1260.

79. Sugiyama J. E., Glass D. J., Yancopoulos G. D., and Hall Z. W. (1997) Laminin-induced acetylcholine receptor clustering: an alternative pathway. J. Cell Biol. 139, 181-191.

80. Martin P. T. and Sanes J. R. (1995) Role for a synapse-specific carbohydrate in agrininduced clustering of acetylcholine receptors. Neuron 14, 743-754.

81. Peng H. B., Ali A. A., Dai Z., Daggett D. F., Raulo E., and Rauvala H. (1995) The role of heparin-binding growth-associated molecule
(HB-GAM) in the postsynaptic induction in cultured muscle cells. J. Neurosci. 15, 3027-3038.

82. Peng H. B., Baker L. P., and Chen Q. (1991) Induction of synaptic development in cultured muscle cells by basic fibroblast growth factor. Neuron 6, 237-246.

83. Bayne E. K., Anderson M. J., and Fambrough D. M. (1984) Extracellular matrix organization in developing muscle: correlation with acetylcholine receptor aggregates. J. Cell Biol. 99, 1486-1501.

84. Patton B. L., Miner J. H., Chiu A. Y., and Sanes J. R. (1997) Distribution and function of laminins in the neuromuscular system of developing, adult, and mutant mice. J. Cell Biol. 139, 1507-1521.

85. Noakes P. G., Gautam M., Mudd J., Sanes J. R., and Merlie J. P. (1995) Aberrant differentiation of neuromuscular junctions in mice lacking slaminin/laminin beta 2. Nature 374, 258-262.

86. Patton B. L., Chiu A. Y., and Sanes J. R. (1998) Synaptic laminin prevents glial entry into the synaptic cleft. Nature 393, 698-701.

87. Denzer A. J., Gesemann M., Schumacher B., and Ruegg M. A. (1995) An amino-terminal extension is required for the secretion of chick agrin and its binding to extracellular matrix. $J$. Cell Biol. 131, 1547-1560.

88. Burgess R. W., Skarnes W. C., and Sanes J. R. (2000) Agrin isoforms with distinct amino termini: differential expression, localization, and function. J. Cell Biol. 151, 41-52.

89. Denzer A. J., Brandenberger R., Gesemann M., Chiquet M., and Ruegg M. A. (1997) Agrin binds to the nerve-muscle basal lamina via laminin. J. Cell Biol. 137, 671-683.

90. Kammerer R. A., Schulthess T., Landwehr R., Schumacher B., Lustig A., Yurchenco P. D., et al. (1999) Interaction of agrin with laminin requires a coiled-coil conformation of the agrin-binding site within the laminin gammal chain. EMBO J. 18, 6762-6770.

91. Denzer A. J., Schulthess T., Fauser C., Schumacher B., Kammerer R. A., Engel J., and Ruegg M. A. (1998) Electron microscopic structure of agrin and mapping of its binding site in laminin-1. EMBO J. 17, 335-343.

92. Burkin D. J., Kim J. E., Gu M., and Kaufman S. J. (2000) Laminin and $\alpha 7$ B1 integrin regulate agrin-induced clustering of acetylcholine receptors. J. Cell Sci. 113, 2877-2886.

93. Jacobson C., Cote P., Rossi S., Rotundo R., and Carbonetto S. (2001) The dystroglycan com- 
plex is necessary for stabilization of acetylcholine receptor clusters at neuromuscular junctions and formation of the synaptic basement membrane. J. Cell Biol. 152, 435-450.

94. Burkin D. J., Gu M., Hodges B. L., Campanelli J. T., and Kaufman S. J. (1998) A functional role for specific spliced variants of the alpha7beta1 integrin in acetylcholine receptor clustering. J. Cell Biol. 143, 1067-1075.

95. Martin P. T. and Sanes J. R. (1997) Integrins mediate adhesion to agrin and modulate agrin signaling. Development 124, 3909-3917.

96. Parkhomovskiy N. and Martin P. T. (2000) Alpha-galactosidase stimulates acetylcholine receptor aggregation in skeletal muscle cells via PNA-binding carbohydrates. Biochem. Biophys. Res. Commun. 270, 899-902.

97. Grow W. A., Ferns M., and Gordon H. (1999) Agrin-independent activation of the agrin signal transduction pathway. J. Neurobiol. 40, 356-365.

98. Grow W. A., Ferns M., and Gordon H. (1999) A mechanism for acetylcholine receptor clustering distinct from agrin signaling. Dev. Neurosci. 21, 436-443.

99. Parkhomovskiy N., Kammesheidt A., and Martin P. T. (2000) N-acetyllactosamine and the CT carbohydrate antigen mediate agrindependent activation of MuSK and acetylcholine receptor clustering in skeletal muscle. Mol. Cell. Neurosci. 15, 380-397.

100. Straub V. and Campbell K. P. (1997) Muscular dystrophies and the dystrophin-glycoprotein complex. Curr. Opin. Neurol. 10, 168-175.

101. Nawrotzki R., Loh N. Y., Ruegg M. A., Davies K. E., and Blake D. J. (1998) Characterisation of alpha-dystrobrevin in muscle. J. Cell Sci. 111, 2595-2605.

102. Kramarcy N. R. and Sealock R. (2000) Syntrophin isoforms at the neuromuscular junction: developmental time course and differential localization. Mol. Cell. Neurosci. 15, 262-274.

103. Deconinck A. E., Potter A. C., Tinsley J. M., Wood S. J., Vater R., Young C., et al (1997) Postsynaptic abnormalities at the neuromuscular junctions of utrophin- deficient mice. J. Cell Biol. 136, 883-894.

104. Lyons P. R. and Slater C. R. (1991) Structure and function of the neuromuscular junction in young adult mdx mice. J. Neurocytol. 20, 969-981.

105. Torres L. F. and Duchen L. W. (1987) The mutant mdx: inherited myopathy in the mouse. Morphological studies of nerves, muscles and end-plates. Brain 110, 269-299.

106. Grady R. M., Teng H., Nichol M. C., Cunningham J. C., Wilkinson R. S., and Sanes J. R. (1997) Skeletal and cardiac myopathies in mice lacking utrophin and dystrophin: a model for Duchenne muscular dystrophy. Cell 90, 729-738.

107. Deconinck A. E., Rafael J. A., Skinner J. A., Brown S. C., Potter A. C., Metzinger L., et al. (1997) Utrophin-dystrophin-deficient mice as a model for Duchenne muscular dystrophy. Cell 90, 717-727.

108. Cote P. D., Moukhles H., Lindenbaum M., and Carbonetto S. (1999) Chimaeric mice deficient in dystroglycans develop muscular dystrophy and have disrupted myoneural synapses. Nat. Genet. 23, 338-342.

109. Grady R. M., Zhou H., Cunningham J. M., Henry M. D., Campbell K. P., and Sanes J. R. (2000) Maturation and maintenance of the neuromuscular synapse: genetic evidence for roles of the dystrophin-glycoprotein complex. Neuron 25, 279-293.

110. Heathcote R. D., Ekman J. M., Campbell K. P., and Godfrey E. W. (2000) Dystroglycan overexpression in vivo alters acetylcholine receptor aggregation at the neuromuscular junction. Dev. Biol. 227, 595-605.

111. Grady R. M., Grange R. W., Lau K. S., Maimone M. M., Nichol M. C., Stull J. T., and Sanes J. R. (1999) Role for alpha-dystrobrevin in the pathogenesis of dystrophin-dependent muscular dystrophies. Nat. Cell Biol. 1, 215-220.

112. Adams M. E., Kramarcy N., Krall S. P., Rossi S. G., Rotundo R. L., Sealock R., and Froehner S. C. (2000) Absence of alpha-syntrophin leads to structurally aberrant neuromuscular synapses deficient in utrophin. J. Cell Biol. 150, 1385-1398.

113. Kameya S., Miyagoe Y., Nonaka I., Ikemoto T., Endo M., Hanaoka K., et al. (1999) alpha1-syntrophin gene disruption results in the absence of neuronal-type nitric-oxide synthase at the sarcolemma but does not induce muscle degeneration. J. Biol. Chem. 274, 2193-2200.

114. Kaplan K. B., Swedlow J. R., Morgan D. O., and Varmus H. E. (1995) c-Src enhances the spreading of src-/- fibroblasts on fibronectin by a kinase-independent mechanism. Genes Dev. 9, 1505-1517.

115. Thomas J. W., Ellis B., Boerner R. J., Knight W. B., White G. C., 2nd, and Schaller M. D. (1998) 
SH2- and SH3-mediated interactions between focal adhesion kinase and Src. J. Biol. Chem. 273, 577-583.

116. Sieg D. J., Ilic D., Jones K. C., Damsky C. H., Hunter T., and Schlaepfer D. D. (1998) Pyk2 and Src-family protein-tyrosine kinases compensate for the loss of FAK in fibronectin-stimulated signaling events but Pyk2 does not fully function to enhance FAK-cell migration. EMBO J. 17, 5933-5947.

117. Balasubramanian S. and Huganir R. L. (1999) Characterization of phosphotyrosine containing proteins at the cholinergic synapse. FEBS Lett. 446, 95-102.

118. Gonzalez M., Ruggiero F. P., Chang Q., Shi Y. J., Rich M. M., Kraner S., and Balice-Gordon R. J. (1999) Disruption of Trkb-mediated signaling induces disassembly of postsynaptic receptor clusters at neuromuscular junctions. Neuron 24, 567-583.

119. Iwasaki Y., Gay B., Wada K., and Koizumi S. (1998) Association of the Src family tyrosine kinase Fyn with TrkB. J. Neurochem. 71, 106-111.

120. Wells D. G., McKechnie B. A., Kelkar S., and Fallon J. R. (1999) Neurotrophins regulate agrin-induced postsynaptic differentiation. Proc. Natl. Acad. Sci. USA 96, 1112-1117.

121. Wagner K. R., Cohen J. B., and Huganir R. L. (1993) The 87K postsynaptic membrane protein from Torpedo is a protein- tyrosine kinase substrate homologous to dystrophin. Neuron 10, 511-522.

122. Missias A. C., Mudd J., Cunningham J. M., Steinbach J. H., Merlie J. P., and Sanes J. R. (1997) Deficient development and maintenance of postsynaptic specializations in mutant mice lacking an 'adult' acetylcholine receptor subunit. Development 124, 5075-5086.

123. Witzemann V., Schwarz H., Koenen M., Berberich C., Villarroel A., Wernig A., et al. (1996) Acetylcholine receptor epsilon-subunit deletion causes muscle weakness and atrophy in juvenile and adult mice. Proc. Natl. Acad. Sci. USA 93, 13,286-13,291.

124. Schwarz H., Giese G., Muller H., Koenen M., and Witzemann V. (2000) Different functions of fetal and adult AChR subtypes for the formation and maintenance of neuromuscular synapses revealed in epsilon-subunit-deficient mice. Eur. J. Neurosci. 12, 3107-3116.

125. Akaaboune M., Culican S. M., Turney S. G., and Lichtman J. W. (1999) Rapid and reversible effects of activity on acetylcholine receptor density at the neuromuscular junction in vivo. Science 286, 503-507.

126. Role L. W. (1992) Diversity in primary structure and function of neuronal nicotinic acetylcholine receptor channels. Curr. Opin. Neurobiol. 2, 254-262.

127. Lindstrom J., Anand R., Gerzanich V., Peng X., Wang F., and Wells G. (1996) Structure and function of neuronal nicotinic acetylcholine receptors. Prog. Brain Res. 109, 125-137.

128. Elgoyhen A. B., Vetter D. E., Katz E., Rothlin C. V., Heinemann S. F., and Boulter J. (2001) alpha 10: A determinant of nicotinic cholinergic receptor function in mammalian vestibular and cochlear mechanosensory hair cells. Proc. Natl. Acad. Sci. USA 98, 3501-3506.

129. Goldman D., Deneris E., Luyten W., Kochhar A., Patrick J., and Heinemann S. (1987) Members of a nicotinic acetylcholine receptor gene family are expressed in different regions of the mammalian central nervous system. Cell 48, 965-973.

130. Sargent P. B. (1993) The diversity of neuronal nicotinic acetylcholine receptors. Annu. Rev. Neurosci. 16, 403-443.

131. Castro N. G. and Albuquerque E. X. (1995) alpha-Bungarotoxin-sensitive hippocampal nicotinic receptor channel has a high calcium permeability. Biophys. J. 68, 516-524.

132. Rogers M. and Dani J. A. (1995) Comparison of quantitative calcium flux through NMDA, ATP, and ACh receptor channels. Biophys. J. 68, 501-506.

133. McGehee D. S., Heath M. J., Gelber S., Devay P., and Role L. W. (1995) Nicotine enhancement of fast excitatory synaptic transmission in CNS by presynaptic receptors. Science 269, 1692-1696.

134. Wonnacott S. (1997) Presynaptic nicotinic ACh receptors. Trends Neurosci. 20, 92-98.

135. Horch H. L. and Sargent P. B. (1995) Perisynaptic surface distribution of multiple classes of nicotinic acetylcholine receptors on neurons in the chicken ciliary ganglion. J. Neurosci. 15, 7778-7795.

136. Skok V. I., Farrugia G., Ermilov L. G., Miller S. M., and Szurszewski J. H. (1998) Patch-clamp recordings of membrane currents evoked during natural synaptic activity in sympathetic neurons. Neuroscience 87, 509-517.

137. Feng G., Steinbach J. H., and Sanes J. R. (1998) Rapsyn clusters neuronal acetylcholine recep- 
tors but is inessential for formation of an interneuronal cholinergic synapse. J. Neurosci. 18, 4166-4176.

138. Jones S., Sudweeks S., and Yakel J. L. (1999) Nicotinic receptors in the brain: correlating physiology with function. Trends Neurosci. 22, 555-561.

139. Corriveau R. A. and Berg D. K. (1993) Coexpression of multiple acetylcholine receptor genes in neurons: quantification of transcripts during development. J. Neurosci. 13, 2662-2671.

140. Conroy W. G. and Berg D. K. (1995) Neurons can maintain multiple classes of nicotinic acetylcholine receptors distinguished by different subunit compositions. J. Biol. Chem. 270, 4424-4431.

141. Ullian E. M., McIntosh J. M., and Sargent P. B. (1997) Rapid synaptic transmission in the avian ciliary ganglion is mediated by two distinct classes of nicotinic receptors. J. Neurosci. 17, 7210-7219.

142. Shoop R. D., Martone M. E., Yamada N., Ellisman M. H., and Berg D. K. (1999) Neuronal acetylcholine receptors with alpha7 subunits are concentrated on somatic spines for synaptic signaling in embryonic chick ciliary ganglia. J. Neurosci. 19, 692-704.

143. Tsen G., Williams B., Allaire P., Zhou Y. D., Ikonomov O., Kondova I., and Jacob M. H. (2000) Receptors with opposing functions are in postsynaptic microdomains under one presynaptic terminal. Nat. Neurosci. 3, 126-132.

144. Zhang Z. W., Coggan J. S., and Berg D. K. (1996) Synaptic currents generated by neuronal acetylcholine receptors sensitive to alpha-bungarotoxin. Neuron 17, 1231-1240.

145. Chang K. T. and Berg D. K. (1999) Nicotinic acetylcholine receptors containing alpha7 subunits are required for reliable synaptic transmission in situ. J. Neurosci. 19, 3701-3710.

146. Liu Q. and Berg D. K. (1999) Actin filaments and the opposing actions of CaM kinase II and calcineurin in regulating alpha7-containing nicotinic receptors on chick ciliary ganglion neurons. J. Neurosci. 19, 10280-10288.

147. Bruses J., Chauvet N., and Rutishauser U. (2001) Membrane lipid rafts are necessary for the maintenance of the (alpha)7 nicotinic acetylcholine receptor in somatic spines of ciliary neurons. J. Neurosci. 21, 504-512.

148. Brown D. A. and London E. (1998) Functions of lipid rafts in biological membranes. Annu. Rev. Cell. Dev. Biol. 14, 111-136.
149. Williams B. M., Temburni M. K., Levey M. S., Bertrand S., Bertrand D., and Jacob M. H. (1998) The long internal loop of the alpha 3 subunit targets nAChRs to subdomains within individual synapses on neurons in vivo. Nat. Neurosci. 1, 557-562.

150. Sargent P. B. and Pang D. Z. (1989) Acetylcholine receptor-like molecules are found in both synaptic and extrasynaptic clusters on the surface of neurons in the frog cardiac ganglion. J. Neurosci. 9, 1062-1072.

151. Rao A., Kim E., Sheng M., and Craig A. M. (1998) Heterogeneity in the molecular composition of excitatory postsynaptic sites during development of hippocampal neurons in culture. J. Neurosci. 18, 1217-1229.

152. Belcher G. and Ryall R. W. (1977) Substance P and Renshaw cells: a new concept of inhibitory synaptic interactions. J. Physiol. 272, 105-119.

153. Wada E., Wada K., Boulter J., Deneris E., Heinemann S., Patrick J., and Swanson L. W. (1989) Distribution of alpha 2, alpha 3, alpha 4, and beta 2 neuronal nicotinic receptor subunit mRNAs in the central nervous system: a hybridization histochemical study in the rat. J. Comp. Neurol. 284, 314-335.

154. Hill J. A., Jr., Zoli M., Bourgeois J. P., and Changeux J. P. (1993) Immunocytochemical localization of a neuronal nicotinic receptor: the beta 2-subunit. J. Neurosci. 13, 1551-1568.

155. Dominguez del Toro E., Juiz J. M., Peng X., Lindstrom J., and Criado M. (1994) Immunocytochemical localization of the alpha 7 subunit of the nicotinic acetylcholine receptor in the rat central nervous system. J. Comp. Neurol. $349,325-342$.

156. Tokuno H., Moriizumi T., Kudo M., and Nakamura Y. (1988) A morphological evidence for monosynaptic projections from the nucleus tegmenti pedunculopontinus pars compacta (TPC) to nigrostriatal projection neurons. Neurosci. Lett. 85, 1-4.

157. Gould E., Woolf N. J., and Butcher L. L. (1989) Cholinergic projections to the substantia nigra from the pedunculopontine and laterodorsal tegmental nuclei. Neuroscience. 28, 611-623.

158. Arroyo-Jimenez M. M., Bourgeois J. P., Marubio L. M., Le Sourd A. M., Ottersen O. P., Rinvik E., et al. (1999) Ultrastructural localization of the alpha4-subunit of the neuronal acetylcholine nicotinic receptor in the rat substantia nigra. J. Neurosci. 19, 6475-6487. 
159. Futami T., Takakusaki K., and Kitai S. T. (1995) Glutamatergic and cholinergic inputs from the pedunculopontine tegmental nucleus to dopamine neurons in the substantia nigra pars compacta. Neurosci. Res. 21, 331-342.

160. Sorenson E. M., Shiroyama T., and Kitai S. T. (1998) Postsynaptic nicotinic receptors on dopaminergic neurons in the substantia nigra pars compacta of the rat. Neuroscience. 87, 659-673.

161. Clarke P. B., Schwartz R. D., Paul S. M., Pert C. B., and Pert A. (1985) Nicotinic binding in rat brain: autoradiographic comparison of $\left[{ }^{3} \mathrm{H}\right]$ acetylcholine, $\left[{ }^{3} \mathrm{H}\right]$ nicotine, and $\left[{ }^{125} \mathrm{I}\right]-$ alpha-bungarotoxin. J. Neurosci. 5, 1307-1315.

162. Picciotto M. R., Zoli M., Rimondini R., Lena C., Marubio L. M., Pich E. M., et al. (1998) Acetylcholine receptors containing the beta2 subunit are involved in the reinforcing properties of nicotine. Nature. 391, 173-177.

163. Zoli M., Lena C., Picciotto M. R., and Changeux J. P. (1998) Identification of four classes of brain nicotinic receptors using beta2 mutant mice. J. Neurosci. 18, 4461-4472.

164. Klink R., de Kerchove d'Exaerde A., Zoli M., and Changeux J. P. (2001) Molecular and physiological diversity of nicotinic acetylcholine receptors in the midbrain dopaminergic nuclei. J. Neurosci. 21, 1452-1463.

165. Okuda H., Shioda S., Nakai Y., Nakayama H., Okamoto M., and Nakashima T. (1993) Immunocytochemical localization of nicotinic acetylcholine receptor in rat hypothalamus. Brain Res. 625, 145-151.

166. Nakayama H., Shioda S., Okuda H., Nakashima T., and Nakai Y. (1995) Immunocytochemical localization of nicotinic acetylcholine receptor in rat cerebral cortex. Brain Res. Mol. Brain Res. 32, 321-328.

167. Nong Y., Sorenson E. M., and Chiappinelli V. A. (1999) Fast excitatory nicotinic transmission in the chick lateral spiriform nucleus. J. Neurosci. 19, 7804-7811.

168. Ullian E. M. and Sargent P. B. (1995) Pronounced cellular diversity and extrasynaptic location of nicotinic acetylcholine receptor subunit immunoreactivities in the chicken pretectum. J. Neurosci. 15, 7012-7023.

169. Alkondon M. and Albuquerque E. X. (1993) Diversity of nicotinic acetylcholine receptors in rat hippocampal neurons. I. Pharmacological and functional evidence for distinct struc- tural subtypes. J. Pharmacol. Exp. Ther. 265, 1455-1473.

170. Zarei M. M., Radcliffe K. A., Chen D., Patrick J. W., and Dani J. A. (1999) Distributions of nicotinic acetylcholine receptor alpha7 and beta2 subunits on cultured hippocampal neurons. Neuroscience 88, 755-764.

171. Gray R., Rajan A. S., Radcliffe K. A., Yakehiro M., and Dani J. A. (1996) Hippocampal synaptic transmission enhanced by low concentrations of nicotine. Nature 383, 713-716.

172. Mulle C., Vidal C., Benoit P., and Changeux J. P. (1991) Existence of different subtypes of nicotinic acetylcholine receptors in the rat habenulo-interpeduncular system. J. Neurosci. 11, 2588-2597.

173. Connolly J. G., Gibb A. J., and Colquhoun D. (1995) Heterogeneity of neuronal nicotinic acetylcholine receptors in thin slices of rat medial habenula. J. Physiol. 484, 87-105.

174. Zhang M., Wang Y. T., Vyas D. M., Neuman R. S., and Bieger D. (1993) Nicotinic cholinoceptor-mediated excitatory postsynaptic potentials in rat nucleus ambiguus. Exp. Brain Res. 96, 83-88.

175. Phelan K. D. and Gallagher J. P. (1992) Direct muscarinic and nicotinic receptor-mediated excitation of rat medial vestibular nucleus neurons in vitro. Synapse 10, 349-358.

176. Xiang Z., Huguenard J. R., and Prince D. A. (1998) Cholinergic switching within neocortical inhibitory networks. Science 281, 985-988.

177. Roerig B., Nelson D. A., and Katz L. C. (1997) Fast synaptic signaling by nicotinic acetylcholine and serotonin 5-HT3 receptors in developing visual cortex. J. Neurosci. 17, 8353-8362.

178. Feller M. B., Wellis D. P., Stellwagen D., Werblin F. S., and Shatz C. J. (1996) Requirement for cholinergic synaptic transmission in the propagation of spontaneous retinal waves. Science 272, 1182-1187.

179. Frotscher M. and Misgeld U. (1989) Characterization of input synapses on intracellularly stained neurons in hippocampal slices: an HRP/EM study. Exp. Brain Res. 75, 327-334.

180. Cobb S. R., Buhl E. H., Halasy K., Paulsen O., and Somogyi P. (1995) Synchronization of neuronal activity in hippocampus by individual GABAergic interneurons. Nature 378, 75-78.

181. Buzsaki G. and Chrobak J. J. (1995) Temporal structure in spatially organized neuronal ensembles: a role for interneuronal networks. Curr. Opin. Neurobiol. 5, 504-510. 
182. Alkondon M., Rocha E. S., Maelicke A., and Albuquerque E. X. (1996) Diversity of nicotinic acetylcholine receptors in rat brain. V. alphaBungarotoxin-sensitive nicotinic receptors in olfactory bulb neurons and presynaptic modulation of glutamate release. J. Pharmacol. Exp. Ther. 278, 1460-1471.

183. Frazier C. J., Rollins Y. D., Breese C. R., Leonard S., Freedman R., and Dunwiddie T. V. (1998) Acetylcholine activates an alpha-bungarotoxin-sensitive nicotinic current in rat hippocampal interneurons, but not pyramidal cells. J. Neurosci. 18, 1187-1195.

184. McQuiston A. R. and Madison D. V. (1999) Nicotinic receptor activation excites distinct subtypes of interneurons in the rat hippocampus. J. Neurosci. 19, 2887-2896.

185. Alkondon M., Pereira E. F., Barbosa C. T., and Albuquerque E. X. (1997) Neuronal nicotinic acetylcholine receptor activation modulates gamma- aminobutyric acid release from CA1 neurons of rat hippocampal slices. J. Pharmacol. Exp. Ther. 283, 1396-1411.

186. Alkondon M., Pereira E. F., Eisenberg H. M., and Albuquerque E. X. (1999) Choline and selective antagonists identify two subtypes of nicotinic acetylcholine receptors that modulate GABA release from CA1 interneurons in rat hippocampal slices. J. Neurosci. 19, 2693-2705.

187. Sudweeks S. N. and Yakel J. L. (2000) Functional and molecular characterization of neuronal nicotinic $\mathrm{ACh}$ receptors in rat $\mathrm{CA} 1$ hippocampal neurons. J. Physiol. 527, 515-528.

188. Hunt S. P. and Schmidt J. (1978) The electron microscopic autoradiographic localization of alpha- bungarotoxin binding sites within the central nervous system of the rat. Brain Res. 142, 152-159.

189. Hunter B. E., de Fiebre C. M., Papke R. L., Kem W. R., and Meyer E. M. (1994) A novel nicotinic agonist facilitates induction of long-term potentiation in the rat hippocampus. Neurosci. Lett. 168, 130-134.

190. Kim J. H. and Huganir R. L. (1999) Organization and regulation of proteins at synapses. Curr. Opin. Cell Biol. 11, 248-254.

191. Kneussel M. and Betz H. (2000) Clustering of inhibitory neurotransmitter receptors at developing postsynaptic sites: the membrane activation model. Trends Neurosci. 23, 429-435.

192. Gorecki D. C., Abdulrazzak H., Lukasiuk K., and Barnard E. A. (1997) Differential expres- sion of syntrophins and analysis of alternatively spliced dystrophin transcripts in the mouse brain. Eur. J. Neurosci. 9, 965-976.

193. Imamura M. and Ozawa E. (1998) Differential expression of dystrophin isoforms and utrophin during dibutyryl-cAMP-induced morphological differentiation of rat brain astrocytes. Proc. Natl. Acad. Sci. USA 95, 6139-6144.

194. O'Connor L. T., Lauterborn J. C., Gall C. M., and Smith M. A. (1994) Localization and alternative splicing of agrin mRNA in adult rat brain: transcripts encoding isoforms that aggregate acetylcholine receptors are not restricted to cholinergic regions. J. Neurosci. 14, 1141-1152.

195. Serpinskaya A. S., Feng G., Sanes J. R., and Craig A. M. (1999) Synapse formation by hippocampal neurons from agrin-deficient mice. Dev. Biol. 205, 65-78.

196. Li Z., Hilgenberg L. G., O'Dowd D. K., and Smith M. A. (1999) Formation of functional synaptic connections between cultured cortical neurons from agrin-deficient mice. J. Neurobiol. 39, 547-557.

197. Ferreira A. (1999) Abnormal synapse formation in agrin-depleted hippocampal neurons. J. Cell Sci. 112, 4729-4738.

198. Bose C. M., Qiu D., Bergamaschi A., Gravante B., Bossi M., Villa A., et al. (2000) Agrin controls synaptic differentiation in hippocampal neurons. J. Neurosci. 20, 9086-9095.

199. Li Z., Massengill J. L., O’Dowd D. K., and Smith M. A. (1997) Agrin gene expression in mouse somatosensory cortical neurons during development in vivo and in cell culture. Neuroscience 79, 191-201.

200. Kroger S. (1997) Differential distribution of agrin isoforms in the developing and adult avian retina. Mol. Cell. Neurosci. 10, 149-161.

201. Koulen P., Honig L. S., Fletcher E. L., and Kroger S. (1999) Expression, distribution and ultrastructural localization of the synapseorganizing molecule agrin in the mature avian retina. Eur. J. Neurosci. 11, 4188-4196.

202. Mann S. and Kroger S. (1996) Agrin is synthesized by retinal cells and colocalizes with gephyrin. Mol. Cell. Neurosci. 8, 1-13.

203. Neumann F. R., Bittcher G., Annies M., Schumacher B., Kroger S., and Ruegg M. A. (2001) An alternative amino-terminus expressed in the central nervous system converts agrin to a type ii transmembrane protein. Mol. Cell. Neurosci. 17, 208-225. 
204. Smith M. A. and O'Dowd D. K. (1994) Cellspecific regulation of agrin RNA splicing in the chick ciliary ganglion. Neuron 12, 795-804.

205. McAvoy M., Smith M. A., and Fujii J. T. (1996) Agrin mRNA expression in the developing chick Edinger-Westphal nucleus. Vis. Neurosci. 13, 293-301.

206. Campagna J. A., Ruegg M. A., and Bixby J. L. (1995) Agrin is a differentiation-inducing "stop signal" for motoneurons in vitro. Neuron 15, 1365-1374.

207. Yang S. H., Armson P. F., Cha J., and Phillips W. D. (1997) Clustering of GABAA receptors by rapsyn $/ 43 \mathrm{kD}$ protein in vitro. Mol. Cell. Neurosci. 8, 430-438.

208. Conroy W. G. and Berg D. K. (1999) Rapsyn variants in ciliary ganglia and their possible effects on clustering of nicotinic receptors. $J$. Neurochem. 73, 1399-1408.

209. Burns A. L., Benson D., Howard M. J., and Margiotta J. F. (1997) Chick ciliary ganglion neurons contain transcripts coding for acetylcholine receptor-associated protein at synapses (rapsyn). J. Neurosci. 17, 5016-5026.

210. Lidov H. G., Byers T. J., Watkins S. C., and Kunkel L. M. (1990) Localization of dystrophin to postsynaptic regions of central nervous system cortical neurons. Nature 348, 725-728.

211. Kim T. W., Wu K., Xu J. L., and Black I. B. (1992) Detection of dystrophin in the postsynaptic density of rat brain and deficiency in a mouse model of Duchenne muscular dystrophy. Proc. Natl. Acad. Sci. USA 89, 11,642-11,644.

212. De Stefano M. E., Zaccaria M. L., Cavaldesi M., Petrucci T. C., Medori R., and Paggi P. (1997) Dystrophin and its isoforms in a sympathetic ganglion of normal and dystrophic mdx mice: immunolocalization by electron microscopy and biochemical characterization. Neuroscience 80, 613-624.

213. Knuesel I., Mastrocola M., Zuellig R. A., Bornhauser B., Schaub M. C., and Fritschy J. M. (1999) Altered synaptic clustering of GABAA receptors in mice lacking dystrophin $(\mathrm{mdx}$ mice). Eur. J. Neurosci. 11, 4457-4462.

214. Blake D. J., Nawrotzki R., Loh N. Y., Gorecki D. C., and Davies K. E. (1998) beta-dystrobrevin, a member of the dystrophin-related protein family. Proc. Natl. Acad. Sci. USA 95, 241-246.

215. Blake D. J., Hawkes R., Benson M. A., and Beesley P. W. (1999) Different dystrophin-like complexes are expressed in neurons and glia. J. Cell Biol. 147, 645-658.

216. Zaccaria M. L., De Stefano M. E., Properzi F., Gotti C., Petrucci T. C., and Paggi P. (1998) Disassembly of the cholinergic postsynaptic apparatus induced by axotomy in mouse sympathetic neurons: the loss of dystrophin and beta-dystroglycan immunoreactivity precedes that of the acetylcholine receptor. J. Neuropathol. Exp. Neurol. 57, 768-779.

217. Zaccaria M. L., De Stefano M. E., Gotti C., Petrucci T. C., and Paggi P. (2000) Selective reduction in the nicotinic acetylcholine receptor and dystroglycan at the postsynaptic apparatus of mdx mouse superior cervical ganglion. J. Neuropathol. Exp. Neurol. 59, 103-112.

218. Peters M. F., Adams M. E., and Froehner S. C. (1997) Differential association of syntrophin pairs with the dystrophin complex. J. Cell Biol. 138, 81-93.

219. Piluso G., Mirabella M., Ricci E., Belsito A., Abbondanza C., Servidei S., et al. (2000) Gamma1- and gamma2-syntrophins, two novel dystrophin-binding proteins localized in neuronal cells. J. Biol. Chem. 275, 15,851-15,860.

220. Ahn A. H., Freener C. A., Gussoni E., Yoshida M., Ozawa E., and Kunkel L. M. (1996) The three human syntrophin genes are expressed in diverse tissues, have distinct chromosomal locations, and each bind to dystrophin and its relatives. J. Biol. Chem. 271, 2724-2730.

221. Smalheiser N. R. and Kim E. (1995) Purification of cranin, a laminin binding membrane protein. Identity with dystroglycan and reassessment of its carbohydrate moieties. J. Biol. Chem. 270, 15,425-15,433.

222. Tian M., Hagg T., Denisova N., Knusel B., Engvall E., and Jucker M. (1997) Laminin-alpha2 chain-like antigens in CNS dendritic spines. Brain Res. 764, 28-38.

223. Knuesel I., Bornhauser B. C., Zuellig R. A., Heller F., Schaub M. C., and Fritschy J. M. (2000) Differential expression of utrophin and dystrophin in CNS neurons: an in situ hybridization and immunohistochemical study. J. Comp. Neurol. 422, 594-611.

224. Gee S. H., Madhavan R., Levinson S. R., Caldwell J. H., Sealock R., and Froehner S. C. (1998) Interaction of muscle and brain sodium channels with multiple members of the syntrophin family of dystrophin-associated proteins. J. Neurosci. 18, 128-137. 
225. Levi S., Vannier C., and Triller A. (1998) Strychnine-sensitive stabilization of postsynaptic glycine receptor clusters. J. Cell Sci. 111, 335-345.

226. Kirsch J. and Betz H. (1998) Glycine-receptor activation is required for receptor clustering in spinal neurons. Nature 392, 717-720.

227. Levi S., Chesnoy-Marchais D., Sieghart W., and Triller A. (1999) Synaptic control of glycine and GABA(A) receptors and gephyrin expression in cultured motoneurons. J. Neurosci. 19, 7434-7449.

228. Rao A., Cha E. M., and Craig A. M. (2000) Mismatched appositions of presynaptic and postsynaptic components in isolated hippocampal neurons. J. Neurosci. 20, 8344-8353.

229. Arenella L. S., Oliva J. M., and Jacob M. H. (1993) Reduced levels of acetylcholine receptor expression in chick ciliary ganglion neurons developing in the absence of innervation. J. Neurosci. 13, 4525-4537.

230. Levey M. S. and Jacob M. H. (1996) Changes in the regulatory effects of cell-cell interactions on neuronal AChR subunit transcript levels after synapse formation. J. Neurosci. 16, 6878-6885.
231. Allison D. W., Gelfand V. I., Spector I., and Craig A. M. (1998) Role of actin in anchoring postsynaptic receptors in cultured hippocampal neurons: differential attachment of NMDA versus AMPA receptors. J. Neurosci. 18, 2423-2436.

232. Chen L., Wang H., Vicini S., and Olsen R. W. (2000) The gamma-aminobutyric acid type A $\left(\mathrm{GABA}_{\mathrm{A}}\right)$ receptor-associated protein (GABARAP) promotes $\mathrm{GABA}_{\mathrm{A}}$ receptor clustering and modulates the channel kinetics. Proc. Natl. Acad. Sci. USA 97, 11557-11562.

233. Ehlers M. D., Fung E. T., O'Brien R. J., and Huganir R. L. (1998) Splice variant-specific interaction of the NMDA receptor subunit NR1 with neuronal intermediate filaments. $J$. Neurosci. 18, 720-730.

234. Garner C. C., Nash J., and Huganir R. L. (2000) PDZ domains in synapse assembly and signalling. Trends Cell Biol. 10, 274-280.

235. Shen L., Liang F., Walensky L. D., and Huganir R. L. (2000) Regulation of AMPA receptor GluR1 subunit surface expression by a $4.1 \mathrm{~N}-$ linked actin cytoskeletal association. J. Neurosci. 20, 7932-7940. 